Copyright (C) 2015-2019. This material is presented to ensure timely dissemination of scholarly and technical work. Copyright and all rights therein are retained by authors or by other copyright holders. All persons copying this information are expected to adhere to the terms and constraints invoked by each author's copyright. In most cases, these works may not be reposted without the explicit permission of the copyright holder.

The following article is the POST-PRINTS version. An updated version will be available when the article is fully published. If you do not have access, you may contact the authors directly for a copy.

The current reference for this work is as follows:

Nadia Olivero, Andrea Greco, Anna Maria Annoni, Patrizia Steca, and Paul Benjamin Lowry (2019). "Does opportunity make the thief? Abilities and moral disengagement in illegal downloading," Behaviour \& Information Technology (BIT) (accepted 13-Jan-2019)

If you have any questions, would like a copy of the final version of the article, or would like copies of other articles we've published, please contact any of us directly, as follows:

\title{
- Dr. Nadia Olivero
}

- Department of Psychology, University of Milano Bicocca, Italy

○ Email: nadia.olivero@unimib.it

○ Website: https://psicologia.unimib.it/en/ugov/personalpage?id $a b=105516$

- Dr. Andrea Greco

○ Postdoctoral research fellow Department of Psychology, University of Milan-Bicocca, Italy

- Email: andrea.greco@unibg.it

o Website: https://www.linkedin.com/in/andrea-greco-742966b0/

- Dr. Anna Maria Annoni

- University of Milano Bicocca, Italy

- Email: a.annoni5@campus.unimib.it

- Dr. Patrizia Steca

- Department of Psychology, University of Milano Bicocca, Italy

- Email: patrizia.steca@unimib.it

○ Website: https://www.linkedin.com/in/patrizia-steca$\underline{1637 \mathrm{a} 72 \mathrm{~b} / \text { ?originalSubdomain }=\mathrm{it}}$

- Professor Paul Benjamin Lowry

○ Pamplin College of Business, Virginia Tech, USA

- Email: Paul.Lowry.PhD@gmail.com

○ Website: https://sites.google.com/site/professorlowrypaulbenjamin/home

- System to request Paul's articles: https://seanacademic.qualtrics.com/SE/?SID=SV 7WCaP0V7FA0GWWx 


\section{Does opportunity make the thief? Abilities and moral disengagement in illegal downloading}

Nadia Olivero ${ }^{1}$, Andrea Greco ${ }^{1}$, Anna Maria Annoni ${ }^{1}$, Patrizia Steca ${ }^{1}$, and Paul Benjamin Lowry $^{2}$

${ }^{1}$ Department of Psychology, University of Milano Bicocca, Italy

${ }^{2}$ Pamplin College of Business, Virginia Tech, Blacksburg, VA, USA

Running title: Abilities and moral disengagement in illegal downloading

DATE: January 12, 2019

SUBMITTED TO: Behaviour and Information Technology

CORRESPONDENCE TO:

Nadia Olivero, Department of Psychology, University of Milano Bicocca, Italy

E-MAIL: nadia.olivero@unimib.it

Contact details of all the authors

Andrea Greco: andrea.greco@unibg.it

Anna Maria Annoni: a.annoni5@campus.unimib.it

Patrizia Steca: patrizia.steca@unimib.it

Paul Benjamin Lowry: Paul.Lowry.PhD@gmail.com 


\title{
Does opportunity make the thief? \\ Abilities and moral disengagement in illegal downloading
}

\begin{abstract}
Recent research has shown that typically law-abiding people perceive the act of illegal downloading as less unethical than other illegal acts. A major thrust of today's digital piracy research is indeed to understand how emerging social norms influence consumer perceptions and lead to rationalisations that justify antinormative behaviour despite moral and ethics. We adopt a model comparison approach to evaluate the impact of moral disengagement mechanisms with respect to the most often used constructs referring to the theory of planned behaviour (TPB) and of moral obligation on intention to pirate. Comparisons between the tested models clearly indicate that moral disengagement plays a significant role in the prediction of piracy. The results also suggest that the practice of illegal downloading is spreading across genders, and that other than moral disengagement, demographic factors of young age, pirating experience, and pirating ability are strong predictors of illegal downloading. When moral disengagement mechanisms are included in the model, intention to pirate is explained by past piracy behaviour, perceived behavioural control, and subjective norms as well as the moral disengagement mechanism of 'euphemistic labelling'. Our findings advance the current understanding of digital piracy and support the design of more effective interventions to counteract its further diffusion.
\end{abstract}

\section{KEYWORDS}

Piracy, digital piracy, illegal file sharing, copyright infringement, social cognitive theory (SCT), neutralisation, moral obligation, morality, theory of planned behaviour (TPB), moral disengagement, perceived behavioural control (PBC), self-efficacy, subjective norms 


\section{INTRODUCTION}

Over the last 15 years, copyright infringements have heavily damaged intellectual property businesses. The 2016 report by the piracy tracking platform $\mathrm{MUSO}^{1}$ revealed that, taking into account the Internet's penetration, digital piracy is a worldwide issue, with some European countries hosting the highest ratio of Internet users involved in illegal downloading (e.g., $46 \%$ of Internet users in Latvia, $22 \%$ in Spain, $18 \%$ in Sweden, $9 \%$ in Italy, $8 \%$ in the United Kingdom, 5\% in the United States). Market analysts have indicated that US\$59 billion in illegal software was downloaded in 2010, \$2.7 billion in workers' earnings and 71,060 jobs are lost each year in the United States due to online piracy, more than $75 \%$ of computers have at least once downloaded illegal applications, and $22 \%$ of the Internet bandwidth is used for piracy worldwide (Go-Gulf, 2011). Reactions from various stakeholders have focused on severe enforcement measures. In the United States, the FBI has declared that any copyright infringement, including infringements without monetary gain, is punishable by up to five years in federal prison and a fine of $\$ 250,000$ (Title 17, United States Code, Sections 501 and 506). Also significant is the media industry's investment in advertising campaigns that communicate warnings about the act of illegal downloading by comparing online piracy to stealing CDs and to seriously illegal acts committed offline (Coyle et al., 2009; Robertson et al., 2012).

Despite these efforts, however, digital piracy continues to grow. Messages aimed at raising ethical concerns and consumers' awareness regarding the illegality of the act appear to have very little effect.

Digital piracy occurs when consumers intentionally share or acquire copyrighted digital goods without paying. It is an intentional act and hence involves the will to act illegally for personal benefit. It therefore seems reasonable to conclude that people who are

\footnotetext{
${ }^{1}$ https://www.muso.com/annual-piracy-reports/
} 
typically law-abiding and exhibit strong moral obligations may adapt their moral judgement to new social norms, like those related to digital piracy. However, research has shown that various measures of personal morality and ethics very often have little predictive power regarding the intention to pirate (Lowry et al., 2017). Consumers engage in unlawful file sharing regardless of their personal morality, because they perceive the act of downloading digital material as somehow less unethical than other illegal acts (Fleming et al., 2017; Hamrick, 2016, Lowry et al., 2017). In Watson and colleagues' (2017) study, illegal digital sharing was not predicted by perceptions of legal risks but rather by the perceived benefits associated with the digital piracy activity. A major thrust of today's digital piracy research is indeed to understand how emerging social norms influence consumer perceptions of illegal downloading and how such norms lead to rationalisations that justify antinormative behaviour despite personal morality and ethics.

The potential for an existing conflict between personal morality and emerging social norms is supported by research that has found a lack of consistency between pirates' beliefs regarding the unethical nature of digital file sharing and the degree to which they experience guilt. De Corte and Van Kenhove (2017) identified distinct segments of pirates characterised by different beliefs that are associated with different degrees and frequencies of piracy behaviours. The majority of the pirates they surveyed - that is, three of the four segmentsconsider piracy unethical but still engage in illegal downloading, and most of them report feeling little or no guilt. A high degree of piracy involvement is associated with a tendency to disengage morally and consequently feel little guilt despite the awareness of the act's illegality (ibid.). Moreover, experimental manipulations showed that communication about the act's illegality did not significantly lower pirating intentions in any segment and that perceived triviality was not affected by any communication strategy. Neither communication about illegality nor communication about the harm caused by piracy changed previous beliefs 
about significance and gravity. In spite of an increased awareness of inflicted harm and an increased perception of illegality, piracy remained an issue of little consequence for all segments (De Corte \& Van Kenhove, 2017).

Copyright infringements associated with peer-to-peer file sharing might have begun as a sort of Internet-subculture activism (Condry, 2004) but are now a widespread phenomenon. Whereas early piracy research described the growth of a 'download culture' consisting of young males with strongly shared norms about freedom and democracy on the Internet (Bhattacharjee et al., 2003; Chiou et al., 2005; Hinduja, 2003), more recent studies have indicated that values supporting piracy as an acceptable behaviour have spread to the majority of consumers (Hamrick, 2016).

Identifying the cognitive mechanisms that explain piracy when divergent values and attitudes still exist should clarify the reasons behind the lack of effectiveness of the many communication efforts made by the industry. Responding to the call for research on neutralisation and moral disengagement mechanisms (Lowry e al., 2017), this article aims to explain the impact of moral disengagement mechanisms on intention to pirate in order to identify the rationalisations associated with users' adaptation to new 'download-culture' values. In the pursuing of this goal we adopt a model comparison approach (Chau \& $\mathrm{Hu}$, 2001; Shiau \& Chau, 2016; Yoon, 2011) to verify what is the incremental contribution of moral disengagement mechanisms with respect to previously established piracy intention models based on the theory of planned behaviour and moral obligation.

The article is structured as follows. First, we argue for a social cognitive integration of the more commonly used predictive models of piracy and introduce the construct of moral disengagement. Second, we present our empirical research to show that accounting for moral disengagement mechanisms improves the understanding of piracy intentions. Last, we discuss the study's implications for public policy and marketing. 


\section{REVIEW OF PREDICTIVE MODELS OF PIRACY: FROM THE THEORY OF PLANNED BEHAVIOUR (TPB) TO SOCIAL COGNITIVE THEORY (SCT)}

Various studies have recommended the adoption of the theory of planned behaviour (TPB) as an ideal framework for the explanation of digital piracy (see Flaming et al., 2017; Kwong \& Lee, 2002; Sang et al. 2015; Yoon, 2012). Among the predictive models of piracy, the most comprehensive approaches have indeed drawn on the TPB and embraced rational perspectives based on cost-benefit calculations and action-outcome expectancies (Lowry et al., 2017; Watson et al., 2015). The TPB is a decision-making model that explains behaviour by three precursors to intention, that is, attitudes, subjective norms, and perceived behavioural control (Ajzen, 1991). According to Fishbein and Ajzen's model (1975), attitudes - that is, dispositions to respond to an object in a consistently favourable or unfavourable manner-develop reasonably from the beliefs people hold about that object. However, attitudes may not reflect behavioural intention when they are in contrast with other normative beliefs, such as beliefs regarding the perceived approval of significant others. In the context of digital piracy, the effect of new download-culture norms on young people, whose need for peer approval is typically high, can have a strong impact on intention. Young people typically exhibit a strong need to engage in peer emulation. It is therefore reasonable to expect, in line with previous studies (Bhattacharjee et al., 2003; Chiou et al., 2005; Hinduja, 2003), that young age will be strongly associated with piracy. Previous research has also shown an important association between perceived behavioural control and young age (Fleming et al., 2017) as well as between behavioural control and gender (Lowry et al., 2017). Young males (students) exhibit higher perceived behavioural control, and the latter appears to be an important predictor of piracy (ibid.). A recent meta-analysis showed that only three of the usual covariates can consistently help in the prediction of piracy: age, gender, and computer self-efficacy or perceived behavioural control (Lowry et al., 2017). Perceived behavioural control and self-efficacy, which are usually treated as synonymous in 
the piracy literature, refer to a person's conviction regarding their actual ability to execute a given act successfully. The idea of perceived behavioural control in the TPB was derived by from Bandura's self-efficacy construct (Ajzen, 1991) to account for the role of selfregulation, performance expectations, and motivation as explained by social cognitive theory (SCT). In the case of piracy, computer self-efficacy and past piracy experience are positively linked (Yoon, 2011). Meta-analytic findings regarding TPB predictive models have shown that perceived behavioural control is more influential in association to greater experience. The higher is the piracy experience the stronger is the effect of perceived behavioural control on piracy (Fleming et al., 2017).

The idea that one learns from past behaviour and that one's experience reinforces motivation toward illegal downloading lends support to the argument that self-regulation mechanisms guide behaviour by virtue of social cognitive factors. Indeed, the literature has suggested that digital piracy might be better explained within the conceptual framework of SCT through socialisation models inclusive of moral-obligation attitudes, social influence, and neutralisation mechanisms (Lowry et al., 2017). Moral obligation refers to the duty or responsibility someone feels honour-bound to perform because of personal beliefs and values. Ajzen (1991) indicated that moral obligation could possibly be introduced into the TPB as an additional determinant of intention when ethical behaviours are concerned. Subsequent piracy studies have indeed found that people's moral beliefs could be associated with the attitudes toward the action and that such beliefs have autonomous explanatory power regarding intention, because they could reduce willingness to conform to peer pressure when the latter is in contrast with personal attitudes (Banerjee et al., 1998; Cronan \& Al-Rafee, 2008; Khang et al., 2012; Kurland, 1995; Leonard \& Cronan, 2001; Randall \& Gibson, 1991). However, further research has provided evidence that personal morality has little explanatory power (Bonner \& O’Higgins, 2010; LaRose \& Kim, 2007; Wingrove et al., 
2011). These inconclusive results can be clarified by a better understanding of current adaptation to emerging social norms. A main goal of the present study is to determine whether moral obligation is still crucial in the prediction of piracy or whether accounting for neutralisation mechanisms will improve prediction and partly explain behavioural intention.

\section{THEORY AND PROPOSED MODELS}

\section{Moral Disengagement and Neutralisation Mechanisms}

SCT (Bandura, 1991) accounts for the impact of social changes on personal thoughts and actions. Starting from social learning theory, Bandura developed the model of triadic reciprocal causation between person, behaviour, and environment, which posits the crucial role of self-reflective processes and self-regulation through action. According to the model, personal beliefs, judgements, and values are constantly exposed to the influence of the social environment, which provides imitation models, feedback (positive or negative outcomes), and social norms. People interact with the environment via actions that result from selfreflective processes based on their own and others' behavioural results (environmental responses to action). Self-regulation is hence a key human capacity for constant learning and adaptation to the environment. Ethics result from rational consideration concerning what is moral; however, moral behaviour is rooted in a self-reactive selfhood rather than in dispassionate abstract reasoning (Bandura, 2002). The constraint of negative self-sanctions for conduct that violates one's moral standards and the support of positive self-sanctions for conduct that is coherent with personal moral standards operate anticipatorily (Bandura, 2001). Self-regulatory processes are therefore crucial for the prediction of ethical behaviours (Aquino \& Reed, 2002). As noted by Bandura (2001, pp. 8-9), 'A complete theory of moral agency must link moral knowledge and reasoning to moral conduct [because] moral reasoning is translated into actions through self-regulatory mechanisms'. Thus, SCT acknowledges the potential difference between moral knowledge and moral behaviour. There 
can be a considerable difference between what people know to be 'wrong' and 'illegal' and how they translate this knowledge into actions. Behavioural intentions, through selfregulatory processes, may deviate considerably from personal morality when contextual factors reinforce new social norms. Contextual adaptation (social learning), however, is not an automatic response. Behavioural change results from cognitive processes that operate in terms of justification and rationalisation. When people engage in actions that conflict with their overall moral judgements, they tend to justify their behaviour by means of neutralisation mechanisms. Moral disengagement is a multidimensional construct that comprises eight mechanisms of moral-control deactivation people use when they engage in immoral behaviours that conflict with their values (Bandura et al., 1999). People tend to justify their moral transgressions according to the cognitive mechanisms of (1) moral justification (based on the appeal to superior aims, which camouflages the reprehensibility of the action), (2) euphemistic labelling (based on the use of language to sanitise actions and often reflecting the role of media communication in the shaping of public opinion), (3) advantageous comparison (based on a comparison to more objectionable actions in order to diminish the seriousness of the action performed), (4) distortion of consequences (based on the negation of the harm and damage caused by the action), (5) displacement of responsibility (based on transferring responsibility for the action to someone else), (6) diffusion of responsibility (based on diffusing responsibility to everyone in order to obscure personal accountability), (7) attribution of blame or guilt (when offenders characterise themselves as victims and denigrate victims as being themselves responsible), and (8) dehumanisation (when offenders devalue victims of maltreatment as not human).

People may use more than one of these mechanisms to justify their actions. Some cognitive mechanisms of moral disengagement may occur consistently within certain social groups and, thus, reflect subcultures' social norms. Kwak and Bandura (1997) observed that 
involvement in antisocial conduct was predicted by moral disengagement and by low selfefficacy in resisting peer pressure.

In our study, we measure the impact of moral disengagement mechanisms (with the exception of dehumanisation, which refers to human victims only and is inapplicable to the digital piracy context) on intention to pirate with the aim of understanding how pirates disengage from moral self-sanction and of evaluating how these mechanisms operate in relation to behavioural intention. Lowry et al.'s (2017) results emphasised the significance of neutralisation mechanisms. Their meta-analysis demonstrated that potential pirates tend to have slightly stronger immoral views but, more importantly, exhibit much more moral disengagement than moral calculation. Hence, the authors concluded that it is not enough to focus on the morality of piracy and that more research is needed to understand and reduce moral disengagement. The extant piracy literature has not clarified the role of moral disengagement with respect to personal morality and TPB constructs for the prediction of piracy. Neutralisation mechanisms that play a role in the prediction of piracy intentions should capture the key reasons for consumer adaptation to emerging norms and should thus reveal areas of potential intervention. Moral disengagement research has been conducted using the general construct both as a unified measure and to uncover the single mechanisms that may play different roles in different contexts. Meta-analysis findings have indicated that piracy studies measuring general moral disengagement had lower effect sizes than studies measuring single disengagement mechanisms (Lowry et al., 2017). In this study, we account for both; however, our main aim is to identify the mechanisms that are the strongest predictors of piracy.

\section{Study Objectives and Proposed Models}

We posit that when people engage in piracy, they are likely to disengage from their moral values by means of justifications that neutralise guilt to the advantage of the performed 
action. Those justifications can reflect rationalisations that people share for specific behavioural dimensions in given sociocultural contexts when cognitive adaptation to new social norms is needed (Bandura, 2001). An important objective of this study is to identify the cognitive mechanism(s) of moral disengagement that may explain piracy intention. To extend previous literature, we thus aim to evaluate the impact of neutralisation mechanisms on the prediction of piracy intention with respect to both the constructs of the TPB model and moral obligation. As for previous extended TPB piracy models (Cronan \& Al-Rafee, 2008), we hypothesise that piracy intention will be predicted by the TPB constructs and will be influenced negatively by moral obligation. Furthermore, we expect that when included in the model, moral disengagement will associate positively with intention and improve its prediction. A secondary objective is to verify the role of covariates such as age, gender, and past behaviour and their relation with moral disengagement in the prediction of piracy. Based on a previous meta-analysis (Lowry et al., 2017), we expect gender differences with respect to perceived behavioural control and past behaviour (that is, males should have pirated more in the past and should score higher on perceived behavioural control).

As discussed, research has indicated that perceived behavioural control and past behaviour are positively linked in the prediction of piracy intention. Their relationship with moral disengagement needs to be explored. High behavioural control could associate with moral disengagement when moral obligation or an unfavourable attitude would otherwise negatively affect intention. Conversely, it could be hypothesised that in conditions of high behavioural control, a strong motivation to perform may reduce the need for any neutralisation mechanism. To test the hypotheses described above (Fig. 1), we test and compare a TPB model (Model 1), a TPB model integrated with moral obligation (Model 2), a TPB model integrated with moral obligation and moral disengagement subcomponents (Model 3), a TPB model integrated with moral obligation and moral disengagement overall 
score (Model 4), and a model in which intention to pirate is predicted by moral disengagement subcomponents only (Model 5).

Figure 1. The hypothesized models explaining Intention to Pirate.

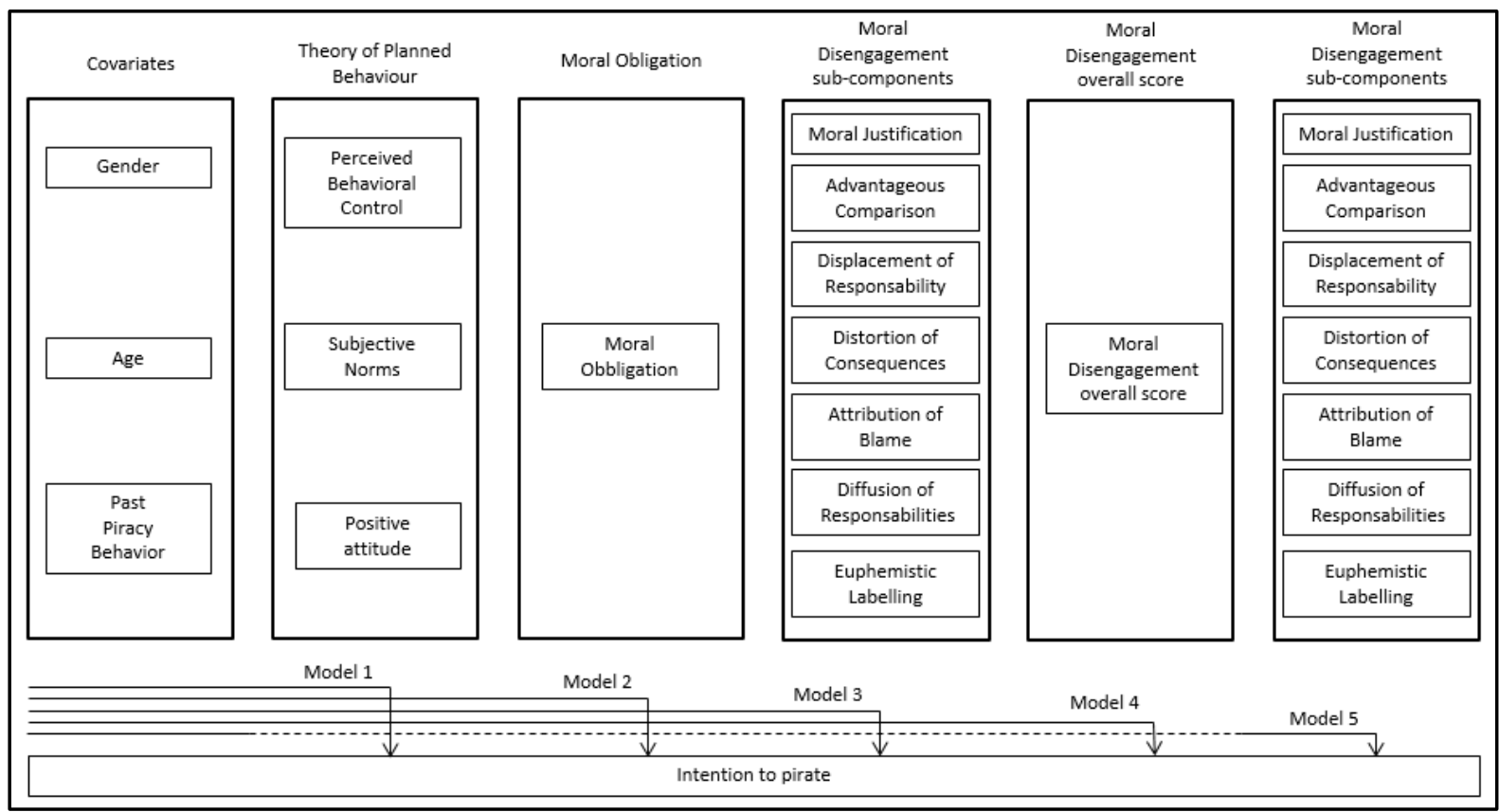

Note: model 1: TPB model with covariates; model 2: TPB model with covariates integrated with Moral Obligation; model 3: TPB model with covariates integrated with Moral Obligation and Moral Disengagement subcomponents; model 4: TPB model with covariates integrated with Moral Obligation and Moral Disengagement overall score; model 5: intention to pirate predicted by Moral Disengagement subcomponents only and covariates.

\section{METHOD}

\section{Participants}

The sample consisted of 396 participants (173 female, 223 male) between 18 and 54 years of age, with a mean age of 23.56 years $(\mathrm{SD}=4.69)$, recruited by a snowball sampling method. They were undergraduate (55.1\%) and postgraduate (44.9\%) students belonging to three top public and private Italian universities. They received course credit for taking part in the study, and all participants verbally agreed to take part in the survey. The study was performed in accordance with the ethical standards established in the 1964 Declaration of Helsinki. Of 
the participants, $10.4 \%$ worked occasionally, $10.2 \%$ were employed full time, $3.1 \%$ had a part-time job, and the other $76.3 \%$ were full-time students. Daily Internet usage frequency was less than two hours for $39.2 \%$, between two and four hours for $35.4 \%$, and between four and six hours for $17.7 \%$; the remaining participants $(7.7 \%)$ reported spending between six and eight hours, or more, online. A total of $81.8 \%$ of the participants had used the Web for more than five years and $18.2 \%$ for less than five years. A total of $78 \%$ of the participants had used software and websites for the downloading of digital material protected by copyright. They downloaded mainly music (58\%), movies (45\%), software $(23 \%)$, and ebooks $(7 \%)$.

\section{Variables and Instruments}

Participants were administered the Italian revised version of Cronan and Al-Rafee's piracy questionnaire (2008), consisting of 59 questions measuring the TPB constructs, moral obligation, and intention to pirate. A measurement of moral disengagement (Bandura et al., 2006) adapted to the context of digital piracy was added to the questionnaire. Thus, the constructs investigated were as follows.

Intention to pirate. Intention to pirate was measured with three items on a 7-point Likert-type scale (Cronan \& Al-Rafee, 2008; Madden, Ellen \& Ajzen, 1992), from $1=$ completely agree to 7 = completely disagree. A sample item is "Would you like to "pirate" digital material in the future (music, software, films, books, etc.)?' The overall score was calculated using the mean scores for all the items of the scale. In line with recommendations by Nunnally and Bernstein (1994) — who defined values of Cronbach's alpha below 0.60 as unacceptable, from 0.60 to 0.70 as sufficient, from 0.70 to 0.80 as moderate, from 0.80 to 0.90 as strong, and 0.90 or higher as excellent — the scale exhibited adequate internal consistency (Cronbach's alpha $=0.79)$.

Positive attitude. A semantic differential scale consisting of 10 bipolar adjectives 
(such as right-wrong, advantageous-disadvantageous, clever-stupid, and dangerous-safe) was used to measure attitude toward piracy on a 7-point Likert-type scale (Bodur et al., 2000; Cronan \& Al-Rafee, 2008; Flannery \& May, 2000; Madden, Ellen \& Ajzen, 1992; Trafimow, 1996). The overall score was calculated using the mean scores for all the items of the scale. The summary score, based on Nunnally and Bernstein's (1994) recommendations, had moderate internal consistency (Cronbach's alpha $=0.74)$.

Subjective norms. Beliefs about the expectations of significant others and willingness to conform were measured with three items on a 7-point Likert-type scale (Cronan \& AlRafee, 2008), from $1=$ completely agree to $7=$ completely disagree. A sample item is 'Many of your friends believe that it is right to "pirate" digital material. Do you agree with them?' The overall score was calculated using the mean scores for all the items of the scale. The summary score, based on Nunnally and Bernstein's (1994) recommendations, had moderate internal consistency (Cronbach's alpha $=0.72)$.

Perceived behavioural control. Three items on a 7-point Likert-type sale (from $1=$ completely agree to $7=$ completely disagree) were used to measure perceived beliefs about being able to perform all the actions necessary to illegally download digital material (Cronan \& Al-Rafee, 2008). A sample item is 'If you wished, it would be easy for you to download digital material illegally'. The overall score was calculated using the mean scores for all the items of the scale. The summary score, based on Nunnally and Bernstein's (1994) recommendations, had strong internal consistency (Cronbach's alpha $=0.84)$.

Moral obligation. This construct was measured by means of three items on a 7-point Likert-type scale (from $1=$ completely agree to $7=$ completely disagree) first developed by Beck and Ajzen (1991) and adapted by Cronan and Al-Rafee (2008). A sample item is 'Do you think that "digital piracy" is immoral?' The overall score was calculated using the mean scores for all the items of the scale. The summary score, based on Nunnally and Bernstein's 
(1994) recommendations, had strong internal consistency (Cronbach's alpha $=0.82$ ).

Past piracy behaviour. Past piracy behaviour was measured by one question-'How much have you "pirated" digital material in the past' —with a 7-point Likert-type scale, from $1=$ very little to $7=\mathrm{a}$ lot $($ Cronan $\&$ Al-Rafee, 2008).

Moral disengagement. We revised the moral disengagement scale developed by Bandura et al. (2006) by removing the dehumanisation mechanism, because it applies to human beings only and thus is not relevant to the context of this study. All the items of the scale were adapted to refer to digital piracy. The scale consisted of three items for each of the seven mechanisms, scored on a 7-point Likert-type scale (ranging from $1=$ completely agree to $7=$ completely disagree). An 'attribution of blame' sample item is 'Piracy should lead the music industry to realise that CD prices are excessive'; a 'distortion of consequences' sample item: 'The consequences of digital piracy are not as serious and severe as people may think'; a 'moral justification' sample item: 'Digital piracy is a way to save money'; a 'euphemistic labelling' sample item: 'I think there is nothing bad about file sharing'; an 'advantageous comparison' sample item: 'Given the level of corruption in society, it is not justifiable to frown upon digital piracy'; a 'diffusion of responsibility' sample item: 'Downloading digital files protected by copyright is not that bad, since everybody does it'; a 'displacement of responsibility' sample item: 'Those who pirate digital material cannot be blamed, since they are unlikely to be legally persecuted'. The overall scores for each mechanism were calculated using the mean scores for all the items of each scale. Moreover, the mean of all the items across the scales was used to obtain a single-score measure of moral disengagement as a general construct. The summary scores, based on Nunnally and Bernstein's (1994) recommendations, exhibited acceptable reliability (Cronbach's alpha for moral justification = 0.71 ; advantageous comparison $=0.71$; distortion of consequences $=0.64$; attribution of blame $=0.76$; diffusion of responsibility $=0.74$; euphemistic labelling $=0.69$ ). The exception 
was displacement of responsibility, which exhibited poor reliability (Cronbach's alpha $=$ 0.56). Moreover, the moral disengagement overall score was found to have excellent internal consistency at baseline (Cronbach's alpha $=.91)$.

\section{DATA ANALYSIS AND RESULTS}

\section{Analysis Approach and Assumptions}

Data analysis was conducted using SPSS Statistics 24 and Mplus 7.0 (Muthén \& Muthén, 1998, 2012). Variables investigated were first analysed, using IBM SPSS, to check the normality of the distribution by calculating mean, standard deviation, and indices of skewness and kurtosis, as West, Finch, and Curran (1995) recommend concern if skewness > 2 and kurtosis $>7$. Next, using IBM SPSS, we calculated a multi-correlation matrix to examine the bivariate correlations among all the measured variables; we used Pearson correlation coefficients for all the relationships except for those among the variables containing gender, for which point-biserial correlation coefficients were used.

Using Mplus software, we then conducted five path analyses to test the hypothesised models shown in Fig. 1. Analyses were performed using maximum likelihood estimation. We used the chi-square test statistic $\left(\chi^{2}\right)$ to verify whether the expected relationships between variables could fit the data. Furthermore, to take into account the chi-square statistic's sensitivity to the sample size, additional goodness of fit indices were used according to $\mathrm{Hu}$ and Bentler's $(1998 ; 1999)$ recommendations, which stipulate that a comparative fit index $(\mathrm{CFI}) \geq 0.95$ indicates good model fit, that values for the root mean square error of approximation $($ RMSEA $) \leq 0.06$ indicate close model fit, and that values for the standardised root mean square residual $(\mathrm{SRMR})<0.08$ generally indicate acceptable model fit.

\section{Preliminary Analysis Results}

Table 1 reports means, standard deviations, skewness, and kurtosis. In line with the recommendations of West, Finch, and Curran (1995), all the scales showed acceptable 
Table 1 Descriptive statistics of considered variables

\begin{tabular}{lcccc}
\hline Variable & Mean & $\begin{array}{c}\text { Standard } \\
\text { Deviation }\end{array}$ & Skewness & Kurtosis \\
\hline Past Piracy Behaviour & 4.41 & 1.91 & -.07 & -1.20 \\
Perceived Behavioural Control & 2.95 & 1.57 & .71 & -.15 \\
Subjective Norms & 3.18 & 1.00 & .38 & .36 \\
Positive Attitude toward Piracy & 3.39 & 1.01 & .58 & 1.48 \\
Moral Obligation & 4.66 & 1.58 & -.27 & -.63 \\
$\begin{array}{l}\text { Moral Disengagement-Attribution } \\
\text { of Blame }\end{array}$ & 2.63 & 1.33 & .93 & .69 \\
$\begin{array}{l}\text { Moral Disengagement-Distortion } \\
\text { of Consequences }\end{array}$ & 3.94 & 1.32 & .07 & -.28 \\
$\begin{array}{l}\text { Moral Disengagement-Moral } \\
\text { Justification }\end{array}$ & 2.78 & 1.14 & .70 & .42 \\
$\begin{array}{l}\text { Moral Disengagement- } \\
\text { Euphemistic Labelling }\end{array}$ & 3.23 & 1.25 & .30 & -.27 \\
$\begin{array}{l}\text { Moral Disengagement- } \\
\text { Advantageous Comparison }\end{array}$ & 3.83 & 1.53 & .13 & -.65 \\
$\begin{array}{l}\text { Moral Disengagement-Diffusion } \\
\text { of Responsibilities }\end{array}$ & 4.42 & 1.38 & -.24 & -.40 \\
$\begin{array}{l}\text { Moral Disengagement- } \\
\text { Displacement of Responsibility }\end{array}$ & & & & \\
$\begin{array}{l}\text { Moral Disengagement-overall } \\
\text { score }\end{array}$ & 3.40 & 1.32 & -.25 & -.21 \\
Intention to Pirate & & 1.00 & .28 & .15 \\
\hline
\end{tabular}

distributions (i.e., skewness $\leq|2|$; kurtosis $\leq|7|$ ).

Moreover, Table 1 shows that past piracy behavior, moral obligation, and the moral disengagement mechanisms of diffusion of responsibilities and displacement of responsibilities present the highest mean values. Furthermore, perceived behavioural control and the moral 
disengagement mechanisms of attribution of blame and moral justification present the lowest mean values.

\section{Correlations among Variables}

Table 2 shows bivariate correlations among considered variables. These correlations were interpreted following Cohen's (1988) guidelines for describing correlation as a measure of effect size (i.e., weak: . $10<|\mathrm{r}|<.29$; moderate: . $30<|\mathrm{r}|<.49$; strong: .50<|r|<1). Correlation analysis provided preliminary support for the relations among the variables measured. Specifically, intention to pirate was positively and strongly associated with past piracy behaviour, perceived behavioural control, subjective norms, and euphemistic labelling, moderately with positive attitude toward piracy, attribution of blame, moral justification, advantageous comparison, diffusion of responsibility, and moral disengagement-overall score, and moderately and negatively with moral obligation; the other correlations were positive and weak.

The variables of the TPB model were positively associated: subjective norms was strongly associated with perceived behavioural control and with positive attitude toward piracy; these last two variables were moderately associated. Past piracy behaviour was positively and moderately associated with the variables of the TPB model, whereas gender and age exhibited positive and weak correlations with them, aside from the correlation between perceived behavioural control and gender that was positive and moderate.

Moral obligation was negatively and strongly associated with euphemistic labelling and moral disengagement-overall score, moderately with all the other variables, aside from the weak correlations with gender, age, and displacement of responsibility. 
Table 2. Pearson Correlations among Considered Variables

\begin{tabular}{|c|c|c|c|c|c|c|c|c|c|c|c|c|c|c|c|}
\hline & 1 & 2 & 3 & 4 & 5 & 6 & 7 & 8 & 9 & 10 & 11 & 12 & 13 & 14 & 15 \\
\hline 1.Gender ${ }^{\mathrm{a}}$ & 1 & & & & & & & & & & & & & & \\
\hline 2.Age & .02 & 1 & & & & & & & & & & & & & \\
\hline 3.Past piracy behaviour & $.23 * * *$ & $.15^{* *}$ & 1 & & & & & & & & & & & & \\
\hline 4.Perceived behavioural control & $.32 * * *$ & $.15^{* *}$ & $.47 * * *$ & 1 & & & & & & & & & & & \\
\hline 5.Subjective norms & $.14^{* *}$ & $.22 * * *$ & $.43 * * *$ & $.57 * * *$ & 1 & & & & & & & & & & \\
\hline 6.Positive attitude toward piracy & $.11 *$ & $.16^{* *}$ & $.39 * * *$ & $.36^{* * *}$ & $.52 * * *$ & 1 & & & & & & & & & \\
\hline 7.Moral obligation & $-.13^{* *}$ & $-.21 * * *$ & $-.37 * * *$ & $-.32 * * *$ & $-.49 * * *$ & $-45^{* * *}$ & 1 & & & & & & & & \\
\hline $\begin{array}{l}\text { 8. Moral disengagement-attribution } \\
\text { of blame }\end{array}$ & .03 & $.13 *$ & $.24 * * *$ & $.25 * * *$ & $.39 * * *$ & $.42 * * *$ & $-.41 * * *$ & 1 & & & & & & & \\
\hline $\begin{array}{l}\text { 9. Moral disengagement-distortion of } \\
\text { consequences }\end{array}$ & $.11 *$ & $.12 *$ & $.15^{* *}$ & $.11^{*}$ & $.28 * * *$ & $.36 * * *$ & $-.34 * * *$ & $.50 * * *$ & 1 & & & & & & \\
\hline $\begin{array}{l}\text { 10. Moral disengagement-moral } \\
\text { justification }\end{array}$ & $.15^{* *}$ & $.13 *$ & $.33 * * *$ & $.38 * * *$ & $.50^{* * *}$ & $.49 * * *$ & $-.45^{* * *}$ & $.71 * * *$ & $.47 * * *$ & 1 & & & & & \\
\hline $\begin{array}{l}\text { 11. Moral disengagement- } \\
\text { euphemistic labelling }\end{array}$ & .08 & $.23 * * *$ & $.43 * * *$ & $.37 * * *$ & $.53 * * *$ & $.59 * * *$ & $-.54 * * *$ & $.53 * * *$ & $.44 * * *$ & $.65 * * *$ & 1 & & & & \\
\hline $\begin{array}{l}\text { 12. Moral disengagement- } \\
\text { advantageous comparison }\end{array}$ & .05 & $.21 * * *$ & $.28 * * *$ & $.15^{* *}$ & $.35^{* * *}$ & $.44 * * *$ & $-.38 * * *$ & $.51 * * *$ & $.55^{* * *}$ & $.55^{* * *}$ & $.56^{* * *}$ & 1 & & & \\
\hline $\begin{array}{l}\text { 13. Moral disengagement-diffusion } \\
\text { of responsibilities }\end{array}$ & $.14^{* *}$ & $.22 * * *$ & $.24 * * *$ & $.18^{* * *}$ & $.40 * * *$ & $.44 * * *$ & $-.36^{* * *}$ & $.46^{* * *}$ & $.56^{* * *}$ & $51 * * *$ & $.53 * * *$ & $.65^{* * *}$ & 1 & & \\
\hline $\begin{array}{l}\text { 14. Moral disengagement- } \\
\text { displacement of responsibility }\end{array}$ & $.12 *$ & $.21 * * *$ & $.24 * * *$ & $.13 * *$ & $.32 * * *$ & $.37 * * *$ & $-.23 * * *$ & $.37 * * *$ & $.43 * * *$ & $.44 * * *$ & $.45 * * *$ & $.59 * * *$ & $.71 * * *$ & 1 & \\
\hline $\begin{array}{l}\text { 15. Moral disengagement-overall } \\
\text { score }\end{array}$ & $.11^{*}$ & $.22 * * *$ & $.33 * * *$ & $.27 * * *$ & $.50 * * *$ & $.58 * * *$ & $-.50 * * *$ & $.73 * * *$ & $.71 * * *$ & $.75^{* * *}$ & $.73 * * *$ & $.81 * * *$ & $.80^{* * *}$ & $.72 * * *$ & 1 \\
\hline 16. Intention to pirate & $.23 * * *$ & $.23 * * *$ & $.65^{* * *}$ & $.56^{* * *}$ & $.57^{* * *}$ & $.47 * * *$ & $-.45 * * *$ & $.38 * * *$ & $.27 * * *$ & $.48 * * *$ & $.57 * * *$ & $.35 * * *$ & $.33 * * *$ & $.27 * * *$ & $.46^{* * *}$ \\
\hline
\end{tabular}

Note: ${ }^{* * *} p<.001 ; * * p<.01 ; * p<.05 ;{ }^{\text {a }}$ Correlations between gender $(0=$ female; $1=$ male $)$ and other variables are point-biserial 
The seven mechanisms of moral disengagement and the moral disengagement-overall score were positively related, with strong and moderate effects; these variables were also correlated positively, with strong and moderate effects, with positive attitude toward piracy and subjective norms, aside from the association between subjective norms and distortion of consequences that was weak. Correlations among the moral disengagement mechanisms, the moral disengagement-overall score and age, past piracy behaviour, perceived behavioural control, subjective norms, and gender were positive, with weak and moderate effects, aside from the associations between gender, attribution of blame, euphemistic labelling, and advantageous comparison that were not significant. Finally, past piracy behaviour was positively and weakly related with gender and age, whereas the association between these last two variables was not significant.

\section{Path Analyses: Pattern of Influence}

Table 3 reports $\beta$, standard errors, $t$-tests, $p$-values, confidence intervals, and standardised parameters estimated for the five path analyses to test the hypothesised models shown in Fig. 1.

Table 3. Summary of Path Analyses for Predicting Intention to Pirate

\begin{tabular}{lccccccc}
\hline & & & & & \multicolumn{2}{c}{$\begin{array}{c}\text { Hower } \\
\text { Higher }\end{array}$} & \multicolumn{2}{c}{ Standardized } \\
& $B$ & S.E. $(B)$ & $t$-value & $p$ & $\begin{array}{c}2.5 \% \\
\text { CI }\end{array}$ & $\beta$ \\
\hline Model 1 & & & & & & & \\
\hline $\begin{array}{l}\text { Gender } \rightarrow \text { Past piracy } \\
\text { behavior }\end{array}$ & 0.868 & .186 & 4.658 & .000 & 0.562 & 1.175 & .226 \\
$\begin{array}{l}\text { Age } \rightarrow \text { Past piracy } \\
\text { behavior }\end{array}$ & 0.059 & .020 & 2.968 & .003 & 0.026 & 0.091 & .144 \\
$\begin{array}{l}\text { Gender } \rightarrow \text { Perceived } \\
\text { behavioral control }\end{array}$ & 0.715 & .139 & 5.161 & .000 & 0.487 & 0.943 & .227 \\
$\begin{array}{l}\text { Age } \rightarrow \text { Perceived } \\
\text { behavioral control }\end{array}$ & 0.029 & .014 & 1.984 & .047 & 0.005 & 0.052 & .086 \\
Past piracy behavior & 0.335 & .036 & 9.196 & .000 & 0.275 & 0.394 & .408
\end{tabular}


RUNNING HEADER: Abilities and moral disengagement in illegal downloading

$\rightarrow$ Perceived

behavioral control

Gender $\rightarrow$ Subjective

norms

$\begin{array}{lllllll}0.088 & .092 & 0958 & .338 & -0.063 & 0.240 & .044\end{array}$

Age $\rightarrow$ Subjective

norms

$\begin{array}{lllllll}0.029 & .014 & 1.984 & .000 & 0.018 & 0.050 & .159\end{array}$

Past piracy behavior

$\rightarrow$ Subjective norms

$\begin{array}{lllllll}0.208 & .024 & 8.608 & .000 & 0.168 & 0.248 & .399\end{array}$

Gender $\rightarrow$ Positive

attitude

$\begin{array}{lllllll}0.052 & .096 & .548 & .583 & -0.015 & 0.210 & .026\end{array}$

Age $\rightarrow$ Positive

attitude

$\begin{array}{lllllll}0.023 & .010 & 2.308 & .020 & 0.007 & 0.039 & .107\end{array}$

Past piracy behavior

$\rightarrow$ Positive attitude

Gender $\rightarrow$ Intention

to pirate

$\begin{array}{lllllll}0.193 & .025 & 7.682 & .000 & 0.152 & 0.234 & .367\end{array}$

$\begin{array}{lllllll}0.104 & .123 & 0.846 & .398 & 0.098 & 0.307 & .030\end{array}$

Age $\rightarrow$ Intention to

pirate

$\begin{array}{lllllll}0.028 & .013 & 2.223 & .026 & 0.007- & 0.049 & .075\end{array}$

Past piracy behavior

$\rightarrow$ Intention to pirate

Perceived behavioral

control $\rightarrow$ Intention

to pirate

Subjective norms $\rightarrow$

Intention to pirate

Positive attitude $\rightarrow$

Intention to pirate

Perceived behavioral

control $\leftrightarrow$ Subjective

norms

Perceived behavioral

control $\leftrightarrow$ Positive

$\begin{array}{lllllll}0.378 & .036 & 10.519 & .000 & 0.319- & 0.437 & .415\end{array}$

$\begin{array}{llllll}0.205 & .048 & 4.230 & .000 & 0.125 & 0.285\end{array}$

$\begin{array}{llllll}0.205 & .048 & 4.230 & .000 & 0.125 & 0.285\end{array}$

.184

$\begin{array}{lllllll}0.344 & .048 & 4.230 & .000 & 0.216 & 0.473 & .197\end{array}$

$\begin{array}{lllllll}0.220 & .068 & 3.215 & .001 & 0.107 & 0.332 & .127\end{array}$

$\begin{array}{lllllll}0.536 & .065 & 8.242 & .000 & 0.429 & 0.664 & .455\end{array}$

attitude

Positive attitude $\leftrightarrow$

Subjective norms

\section{Model 2}

$\begin{array}{lccccccc}\begin{array}{l}\text { Gender } \rightarrow \text { Past piracy } \\ \text { behavior }\end{array} & 0.868 & .186 & 4.658 & .000 & 0.562 & 1.175 & .226 \\ \begin{array}{l}\text { Age } \rightarrow \text { Past piracy } \\ \text { behavior }\end{array} & 0.059 & .020 & 2.968 & .003 & 0.026 & 0.091 & .144 \\ \begin{array}{l}\text { Gender } \rightarrow \text { Perceived } \\ \text { behavioral control }\end{array} & 0.715 & .139 & 5.161 & .000 & 0.487 & 0.943 & .227 \\ \begin{array}{l}\text { Age } \rightarrow \text { Perceived } \\ \text { behavioral control }\end{array} & 0.029 & .014 & 1.1983 & .047 & 0.005 & 0.052 & .086 \\ \begin{array}{l}\text { Past piracy behavior } \\ \rightarrow \text { Perceived }\end{array} & 0.335 & .036 & 9.196 & .000 & 0.275 & 0.394 & .408\end{array}$


RUNNING HEADER: Abilities and moral disengagement in illegal downloading

behavioral control

Gender $\rightarrow$ Subjective

norms

$\begin{array}{lllllll}0.088 & .092 & 0.958 & .338 & -0.063 & 0.240 & .044\end{array}$

Age $\rightarrow$ Subjective

norms

$\begin{array}{llllll}0.034 & .010 & 3.517 & .000 & 0.018 & 0.050\end{array}$

.159

Past piracy behavior

$\rightarrow$ Subjective norms

$\begin{array}{llllllll}0.208 & .024 & 8.608 & .000 & 0.168 & 0.248 & .399\end{array}$

Gender $\rightarrow$ Positive

attitude

$\begin{array}{lllllll}0.052 & .096 & 0.548 & .583 & -0.105 & 0.210 & .026\end{array}$

Age $\rightarrow$ Positive

attitude

$\begin{array}{llllllll}0.023 & .010 & 2.308 & .020 & 0.007 & 0.039 & .107\end{array}$

Past piracy behavior

$\rightarrow$ Positive Attitude

$\begin{array}{llllllll}0.193 & .025 & 7.682 & .000 & 0.152 & 0.234 & .367\end{array}$

Gender $\rightarrow$ Moral

obligation

Age $\rightarrow$ Moral

obligation

Past piracy behavior

$\rightarrow$ Moral obligation

Perceived behavioral

control $\rightarrow$ Moral

obligation

Subjective norms $\rightarrow$

Moral obligation

Positive attitude $\rightarrow$

Moral obligation

Gender $\rightarrow$ Intention

to pirate

$\begin{array}{lllllll}-0.134 & .139 & -0.963 & .335 & -0.362 & 0.095 & -.042\end{array}$

$\begin{array}{lllllll}-0.030 & .014 & -2.124 & .033 & -.054 & -0.007 & -.090\end{array}$

$\begin{array}{lllllll}-.113 & .041 & -2.779 & .005 & -0.179 & -0.046 & -.137\end{array}$

Age $\rightarrow$ Intention to

pirate

Past piracy behavior

$\rightarrow$ Intention to pirate

Perceived behavioral control $\rightarrow$ Intention

to pirate

Subjective norms $\rightarrow$ Intention to pirate

Positive attitude $\rightarrow$

Intention to pirate

Moral obligation $\rightarrow$

Intention to pirate

Perceived behavioral

control $\leftrightarrow$ Subjective

norms

Perceived behavioral

control $\leftrightarrow$ Positive

$\begin{array}{lllllll}0.036 & .055 & 0.659 & .510 & -0.054 & 0.126 & .036 \\ -0.486 & .088 & -5.530 & .000 & -0.631 & -0.342 & -.310 \\ -0.363 & .077 & -4.716 & .000 & -0.490 & -0.237 & -.233 \\ 0.089 & .122 & 0.725 & .469 & -0.113 & 0.290 & .025 \\ 0.025 & .013 & 1.951 & .051 & 0.004 & 0.045 & .066 \\ 0.365 & .036 & 10.145 & .000 & 0.306 & 0.424 & .400 \\ 0.209 & .048 & 4.352 & .000 & 0.130 & 0.288 & .188 \\ 0.288 & .080 & 3.584 & .000 & 0.156 & 0.420 & .165 \\ 0.177 & .070 & 2.549 & .011 & 0.063 & 0.292 & .102 \\ -0.116 & .044 & -2.634 & .008 & -0.189 & -0.044 & -.105 \\ 0.536 & .065 & 8.242 & .000 & 0.429 & 0.643 & .455 \\ 0.255 & .063 & 4.049 & .000 & 0.151 & 0.358 & .208\end{array}$


RUNNING HEADER: Abilities and moral disengagement in illegal downloading

attitude

Positive attitude $\leftrightarrow$

Subjective norms

$\begin{array}{lllllll}0.330 & .044 & 7.481 & .000 & 0.258 & 0.403 & .406\end{array}$

\section{Model 3}

Gender $\rightarrow$ Past piracy

behavior

$\begin{array}{lllllll}0.868 & .186 & 4.658 & .000 & 0.562 & 1.175 & .226\end{array}$

Age $\rightarrow$ Past piracy

behavior

$\begin{array}{lllllll}0.059 & .020 & 2.968 & .003 & 0.026 & 0.091 & .144\end{array}$

Gender $\rightarrow$ Perceived

behavioral control

$\begin{array}{lllllll}0.715 & .139 & 5.161 & .000 & 0.487 & 0.943 & .227\end{array}$

Age $\rightarrow$ Perceived

behavioral control

$\begin{array}{lllllll}0.029 & .014 & 1.983 & .047 & 0.005 & 0.052 & .086\end{array}$

Past piracy behavior

$\rightarrow$ Perceived

$\begin{array}{lllllll}0.335 & .036 & 9.196 & .000 & 0.275 & 0.394 & .408\end{array}$

behavioral control

Gender $\rightarrow$ Subjective

norms

$\begin{array}{llllllll}0.088 & .092 & 0.958 & .338 & 0.168 & 0.240 & .044\end{array}$

Age $\rightarrow$ Subjective

norms

$\begin{array}{lllllll}0.034 & .010 & 3.517 & .000 & 0.018 & 0.050 & .159\end{array}$

Past piracy behavior

$\rightarrow$ Subjective norms

$\begin{array}{llllllll}0.208 & .024 & 8.608 & .000 & -0.063 & 0.240 & .399\end{array}$

Gender $\rightarrow$ Positive

attitude

$\begin{array}{lllllll}0.052 & .096 & 0.548 & .583 & -0.105 & 0.210 & .026\end{array}$

Age $\rightarrow$ Positive

attitude

$\begin{array}{llllllll}0.023 & .010 & 2.308 & .020 & 0.007 & 0.039 & .07\end{array}$

Past piracy behavior

$\rightarrow$ Positive Attitude

$\begin{array}{llllllll}0.193 & .025 & 7.682 & .000 & 0.152 & 0.234 & .367\end{array}$

Gender $\rightarrow$ Moral

obligation

$\begin{array}{lllllll}0-.134 & .139 & -0.963 & .335 & -0.362 & 0.095 & -.042\end{array}$

Age $\rightarrow$ Moral

obligation

$\begin{array}{lllllll}0-.030 & .014 & -2.124 & .033 & -0.054 & -0.007 & -.090\end{array}$

Past piracy behavior

$\rightarrow$ Moral obligation

$\begin{array}{lllllll}-0.113 & .041 & -2.779 & .005 & -0.179 & -0.046 & -.137\end{array}$

Perceived behavioral

control $\rightarrow$ Moral

obligation

Subjective norms $\rightarrow$

Moral obligation

$0.036 \quad .055$

.659

$.510-0.054$

0.126

.036

Positive attitude $\rightarrow$

Moral obligation

$\begin{array}{lllllll}-0.486 & .088 & -5.530 & .000 & -0.631 & -0.342 & -.310\end{array}$

Gender $\rightarrow$ Attribution

of blame

Age $\rightarrow$ Attribution of

blame

$\begin{array}{lllllll}-0.363 & .077 & -4.716 & .000 & 0.490 & -0.237 & -.233\end{array}$

$\begin{array}{lllllll}-0.151 & .124 & -1.217 & .223 & -0.354 & 0.053 & -.056\end{array}$

$\begin{array}{lllllll}0.001 & .013 & 0.093 & .926 & -0.020 & 0.022 & .004\end{array}$

Past piracy behavior

$\rightarrow$ Attribution of

$-0.003$

$.036-0.085$

$\begin{array}{lll}.932 & -0.063 & 0.057\end{array}$

$-.004$ 
RUNNING HEADER: Abilities and moral disengagement in illegal downloading

blame

Perceived behavioral

control $\rightarrow$ Attribution

$\begin{array}{lllllll}0.019 & .049 & 0.384 & .701 & -0.061 & 0.099 & .022\end{array}$

of blame

Subjective norms $\rightarrow$

Attribution of blame

Positive attitude $\rightarrow$

Attribution of blame

Moral obligation $\rightarrow$

Attribution of blame

Gender $\rightarrow$ Distortion

of consequences

Age $\rightarrow$ Distortion of consequences

Past piracy behavior

$\rightarrow$ Distortion of consequences

Perceived behavioral

control $\rightarrow$ Distortion

of consequences

Subjective norms $\rightarrow$

Distortion of

$0.206 \quad .081$

2.538

.011

$0.073 \quad 0.340$

.154

$\begin{array}{lllllll}0.313 & .070 & 4.446 & .000 & 0.197 & 0.429 & .236\end{array}$

$-0.196$

.045

$-4395$

$\begin{array}{lll}.000 & -0.270 & -0.123\end{array}$

$-.231$

0.220

.129

1.708

$\begin{array}{lll}.087 & 0.008 & 0.431\end{array}$

.083

$$
0.009
$$

$.013 \quad 0.676$

$\begin{array}{lll}.499 & -0.013 & 0.031\end{array}$

.032

$-0.022$

.038

$-0.590$

$\begin{array}{lll}.555 & -0.085 & 0.040\end{array}$

$-.032$

$-0.108$

.051

$-2.127$

$\begin{array}{lll}.033 & -0.191 & -0.024\end{array}$

$-.128$

consequences

0.163

.084

1.935

.052

0.024

0.302

.123

Positive attitude $\rightarrow$

Distortion of

$$
0.324
$$

.073

4.420

.000

0.203

0.444

.247

consequences

Moral obligation $\rightarrow$

Distortion of

$-0.14$

035

$-3.958$

$\begin{array}{lll}.000 & -0.246 & -0.093\end{array}$

$-.201$

consequences

Gender $\rightarrow$ Moral

justification

0.090

$.098 \quad 0.915$

$\begin{array}{lll}.360 & -0.072 & 0.251\end{array}$

.039

Age $\rightarrow$ Moral

justification

$-0.00$

.010

$-0.377$

$\begin{array}{lll}.706 & -0.020 & 0.013\end{array}$

$-.016$

Past piracy behavior

$\rightarrow$ Moral justification

0.015

$$
.029
$$

0.502

$\begin{array}{lll}.615 & -0.033 & 0.062\end{array}$

.024

Perceived behavioral

control $\rightarrow$ Moral

justification

Subjective norms $\rightarrow$

Moral justification

Positive attitude $\rightarrow$

Moral justification

Moral obligation $\rightarrow$

Moral justification

Gender $\rightarrow$

Euphemistic labelling

$\begin{array}{lllllll}0.058 & .039 & 1.513 & .130 & -0.005 & 0.122 & .080 \\ 0.249 & .064 & 3.858 & .000 & 0.143 & 0.355 & .218 \\ 0.287 & .056 & 5.130 & .000 & 0.195 & 0.379 & .253 \\ -0.141 & .035 & -3.958 & .000 & -0.199 & -0.082 & -.193 \\ -0.125 & .096 & -1.297 & .195 & -0.283 & 0.034 & -.050\end{array}$


RUNNING HEADER: Abilities and moral disengagement in illegal downloading

Age $\rightarrow$ Euphemistic

labelling

Past piracy behavior

$\rightarrow$ Euphemistic

labelling

Perceived behavioral

control $\rightarrow$

Euphemistic labelling

Subjective norms $\rightarrow$

Euphemistic labelling

Positive attitude $\rightarrow$

Euphemistic labelling

Moral obligation $\rightarrow$

Euphemistic labelling

Gender $\rightarrow$

Advantageous

comparison

Age $\rightarrow$ Advantageous

comparison

Past piracy behavior

$\rightarrow$ Advantageous

comparison

Perceived behavioral

control $\rightarrow$

Advantageous

comparison

Subjective norms $\rightarrow$

Advantageous

comparison

Positive attitude $\rightarrow$

Advantageous

comparison

Moral obligation $\rightarrow$

Advantageous

comparison

Gender $\rightarrow$ Diffusion

of responsibility

Age $\rightarrow$ Diffusion of

responsibility

Past piracy behavior

$\rightarrow$ Diffusion of

responsibility

Perceived behavioral

control $\rightarrow$ Diffusion

of responsibility

Subjective norms $\rightarrow$

$-0.019$

.010

1.932

.053

0.003

0.035

.072

0.080

.028

2.834

.005

0.034

0.127

.123

0.027

.038

0.719

.472

$-0.035$

0.089

.034

0.193

.063

3.049

.002

0.089

0.297

.154

0.412

.055

7.526

.000

$0.322 \quad 0.502$

.332

$-0.199$

.035

$-5.728$

$\begin{array}{lll}.000 & -0.256 & -0.142\end{array}$

$-.250$

0.005

.141

.034

$\begin{array}{lll}.973 & -0.228 & 0.237\end{array}$

.002

0.035

.015

2.411

.016

0.011

0.059

.107

0.08

$$
.042
$$

2.006

.044

0.015

0.152

.104

$-0.14$

$$
.056
$$

$-2.536$

.011

$\begin{array}{ll}-0.232 & -0.049\end{array}$

$-.144$

0.205

.093

2.208

.027

0.052

0.358

.134

0.428

.080

5.316

.000

0.295

0.560

.281

$-0.17$

$$
.051
$$

$-3.326$

.00

$-0.254 \quad-0.086$

$-.174$

$$
0.28
$$

127

2.218

.026

0.073

0.491

.101

0.03

013

2.583

.009

$0.012 \quad 0.055$

.114

$\begin{array}{lllllll}0.011 & .037 & 1.667 & .764 & -0.050 & 0.073 & .015\end{array}$

$\begin{array}{rrrrrrr}-0.137 & .050 & -2.740 & .006 & -0.219 & -0.055 & -.155 \\ 0.345 & .083 & 4.142 & .000 & 0.208 & 0.483 & .249\end{array}$


RUNNING HEADER: Abilities and moral disengagement in illegal downloading

Diffusion of

responsibility

Positive attitude $\rightarrow$

Diffusion of

0.379

.072

5.248

.000

$0.261 \quad 0.498$

.276

responsibility

Moral obligation $\rightarrow$

Diffusion of

$-0.100$

$.046 \quad-2.179$

.029

$\begin{array}{ll}-0.176 & -0.025\end{array}$

$-.113$

responsibility

Gender $\rightarrow$

Displacement of

0.242

.127

1.897

.057

$0.032 \quad 0.451$

.091

responsibility

Age $\rightarrow$ Displacement

of responsibility

$\begin{array}{lllllll}0.039 & .013 & 2.970 & .003 & 0.017 & 0.060 & .138\end{array}$

Past piracy behavior

$\rightarrow$ Displacement of

responsibility

$\begin{array}{lllllll}0.063 & .037 & 1.667 & .095 & 0.001 & 0.124 & .090\end{array}$

Perceived behavioral

control $\rightarrow$

Displacement of

$\begin{array}{lllllll}-0.140 & .050 & -2.800 & .005 & -0.223 & -0.058 & -.166\end{array}$

responsibility

Subjective norms $\rightarrow$

Displacement of

responsibility

Positive attitude $\rightarrow$

Displacement of

responsibility

Moral obligation $\rightarrow$

Displacement of

responsibility

Gender $\rightarrow$ Intention

to pirate

Age $\rightarrow$ Intention to

pirate

Past piracy behavior

$\rightarrow$ Intention to pirate

Perceived behavioral

control $\rightarrow$ Intention

to pirate

Subjective norms $\rightarrow$

Intention to pirate

Positive attitude $\rightarrow$

Intention to pirate

Moral obligation $\rightarrow$

Intention to pirate

Attribution of blame

$\rightarrow$ Intention to pirate

$\begin{array}{ccccccc}0.276 & .084 & 3.302 & .001 & 0.139 & 0.414 & .209 \\ 0.337 & .073 & 4.644 & .000 & 0.218 & 0.456 & .257 \\ 0.007 & .046 & 0.157 & .875 & -0.069 & 0.083 & .009 \\ 0.129 & .121 & 1.068 & .286 & -0.070 & 0.329 & .037 \\ 0.022 & .012 & 1.762 & .078 & 0.001 & 0.042 & .059 \\ 0.347 & .035 & 9.779 & .000 & 0.288 & 0.405 & .380 \\ 0.189 & .048 & 3.962 & .000 & 0.111 & 0.268 & .170 \\ 0.221 & .080 & 2.753 & .006 & 0.089 & 0.352 & .126 \\ 0.045 & .073 & 0.620 & .535 & -0.075 & 0.166 & .026 \\ -0.041 & .045 & -0.909 & .363 & -0.116 & 0.033 & -.037 \\ 0.040 & .062 & 0.638 & .524 & -0.063 & 0.142 & .030\end{array}$


RUNNING HEADER: Abilities and moral disengagement in illegal downloading

Distortion of

consequences $\rightarrow$

0.023

.055

0.414

$.679-0.068$

0.114

.017

Intention to pirate

Moral justification $\rightarrow$

Intention to pirate

0.078

.081

0.961

$.336-0.056$

0.212

.051

Euphemistic labelling

$\rightarrow$ Intention to pirate

0.278

.071

3.940

.000

$0.162 \quad 0.394$

.199

Advantageous

comparison $\rightarrow$

Intention to pirate

Diffusion of

responsibility $\rightarrow$

Intention to pirate

Displacement of

responsibility $\rightarrow$

Intention to pirate

$-0.018$

055

$-0.332$

.740

$-0.108$

0.072

$-.016$

$-0.00$

066

$-0.020$

$.984-0.111$

0.108

$-.001$

$-0.049$

$$
.06
$$

$-0.783$

.434

$-0.151$

0.054

$-.037$

Perceived behavioral

control $\leftrightarrow$ Subjective

norms

Perceived behavioral control $\leftrightarrow$ Positive attitude

Positive attitude $\leftrightarrow$

Subjective norms

Attribution of blame

$\leftrightarrow$ Distortion of consequences

Attribution of blame

$\leftrightarrow$ Moral justification

$$
0.536
$$

8.242

.000

0.429

0.634

.455

$\begin{array}{lllllll}0.255 & .063 & 4.049 & .000 & 0.151 & 0.358 & .208\end{array}$

0.33

$$
.044
$$

7.481

.000

$0.258 \quad 0.403$

.406

Attribution of blame

$\leftrightarrow$ Euphemistic

labelling

Attribution of blame

$\leftrightarrow$ Advantageous

comparison

$\begin{array}{lllllll}0.522 & .073 & 7.105 & .000 & 0.401 & 0.643 & .382 \\ 0.627 & .061 & 10.258 & .000 & 0.527 & 0.728 & .602\end{array}$

$\begin{array}{lllllll}0.302 & .054 & 5.642 & .000 & 0.214 & 0.390 & .296\end{array}$

$\begin{array}{lllllll}0.535 & .080 & 6.676 & .000 & 0.403 & 0.666 & .356\end{array}$

Attribution of blame

$\leftrightarrow$ Diffusion of

responsibility

Attribution of blame

$\leftrightarrow$ Displacement of

responsibility

Distortion of

consequences $\leftrightarrow$

Moral justification

Distortion of

consequences $\leftrightarrow$

$\begin{array}{lllllll}0.401 & .071 & 5.670 & .000 & 0.285 & 0.517 & .297\end{array}$

$\begin{array}{lllllll}0.329 & .070 & 4.695 & .000 & 0.213 & 0.444 & .243\end{array}$

$\begin{array}{lllllll}0.354 & .057 & 6.179 & .000 & 0.260 & 0.449 & .327\end{array}$

$\begin{array}{lllllll}0.277 & .055 & 5.028 & .000 & 0.187 & 0.368 & .261\end{array}$ 
RUNNING HEADER: Abilities and moral disengagement in illegal downloading

Euphemistic labelling

Distortion of

consequences $\leftrightarrow$

Advantageous

$\begin{array}{llllll}0.685 & .086 & 7.998 & .000 & 0.544 & 0.826\end{array}$

.439

comparison

Distortion of

consequences $\leftrightarrow$

Diffusion of

0.629

.077

8.146

.000

0.502

0.756

.449

responsibility

Distortion of

consequences $\leftrightarrow$

Displacement of

$0.460 \quad 074$

$6.188 \quad .000$

$0.338 \quad 0.583$

.327

responsibility

Moral justification $\leftrightarrow$

Euphemistic labelling

0.343

Moral justification $\leftrightarrow$

Advantageous

0.468

comparison

Moral justification $\leftrightarrow$

Diffusion of

$0.346 \quad .057$

6.125

.000

$0.253 \quad 0.439$

.324

responsibility

Moral justification $\leftrightarrow$

Displacement of

$0.325 \quad .056$

5.765

.000

0.232

0.418

.303

responsibility

Euphemistic labelling

$\leftrightarrow$ Advantageous

comparison

$\begin{array}{lllllll}0.413 & .062 & 6.632 & .000 & 0.310 & 0.515 & .353\end{array}$

Euphemistic labelling

$\leftrightarrow$ Diffusion of

$0.333 \quad .055$

6.026

.000

$0.242 \quad 0.424$

.318

responsibility

Euphemistic labelling

$\leftrightarrow$ Displacement of

responsibility

Advantageous

comparison $\leftrightarrow$

Diffusion of

responsibility

Advantageous

comparison $\leftrightarrow$

Displacement of

0.29

.055

5.350

.000

$0.203 \quad 0.384$

.279

responsibility

Diffusion of

responsibility $\leftrightarrow$

Displacement of

0.880

0.825

.088

9.395

.000

$0.681 \quad 0.970$

.536

responsibility

\section{Model 4}


RUNNING HEADER: Abilities and moral disengagement in illegal downloading

\begin{tabular}{|c|c|c|c|c|c|c|c|}
\hline $\begin{array}{l}\text { Gender } \rightarrow \text { Past piracy } \\
\text { behavior }\end{array}$ & 0.868 & .186 & 4.658 & .000 & 0.562 & 1.175 & .226 \\
\hline $\begin{array}{l}\text { Age } \rightarrow \text { Past piracy } \\
\text { behavior }\end{array}$ & 0.059 & .020 & 2.968 & .003 & 0.026 & 0.091 & .144 \\
\hline $\begin{array}{l}\text { Gender } \rightarrow \text { Perceived } \\
\text { behavioral control }\end{array}$ & 0.715 & .139 & 5.161 & .000 & 0.487 & 0.943 & .227 \\
\hline $\begin{array}{l}\text { Age } \rightarrow \text { Perceived } \\
\text { behavioral control }\end{array}$ & 0.029 & .014 & 1.984 & .047 & 0.005 & 0.052 & .086 \\
\hline $\begin{array}{l}\text { Past piracy behavior } \\
\rightarrow \text { Perceived } \\
\text { behavioral control }\end{array}$ & 0.335 & .036 & 9.196 & .000 & 0.275 & 0.394 & .408 \\
\hline $\begin{array}{l}\text { Gender } \rightarrow \text { Subjective } \\
\text { norms }\end{array}$ & 0.088 & .092 & 0.958 & .338 & -0.063 & 0.240 & .044 \\
\hline $\begin{array}{l}\text { Age } \rightarrow \text { Subjective } \\
\text { norms }\end{array}$ & 0.034 & .010 & 3.517 & .000 & 0.018 & 0.050 & .159 \\
\hline $\begin{array}{l}\text { Past piracy behavior } \\
\rightarrow \text { Subjective norms }\end{array}$ & 0.208 & .024 & 8.608 & .000 & 0.168 & 0.248 & .399 \\
\hline $\begin{array}{l}\text { Gender } \rightarrow \text { Positive } \\
\text { attitude }\end{array}$ & 0.052 & .096 & 0.548 & .584 & -0.105 & 0.210 & .026 \\
\hline $\begin{array}{l}\text { Age } \rightarrow \text { Positive } \\
\text { attitude }\end{array}$ & 0.023 & .010 & 3.517 & .020 & 0.007 & 0.039 & 107 \\
\hline $\begin{array}{l}\text { Past piracy behavior } \\
\rightarrow \text { Positive Attitude }\end{array}$ & 0.193 & .025 & 7.682 & .000 & 0.152 & 0.234 & .367 \\
\hline $\begin{array}{l}\text { Gender } \rightarrow \text { Moral } \\
\text { obligation }\end{array}$ & -0.134 & .139 & -0.963 & .335 & -0.362 & 0.095 & -.042 \\
\hline $\begin{array}{l}\text { Age } \rightarrow \text { Moral } \\
\text { obligation }\end{array}$ & -0.030 & .014 & -2.124 & .033 & -0.054 & -0.007 & -.090 \\
\hline $\begin{array}{l}\text { Past piracy behavior } \\
\rightarrow \text { Moral obligation }\end{array}$ & -0.113 & .041 & .2 .779 & .005 & -0.179 & -0.046 & -.137 \\
\hline $\begin{array}{l}\text { Perceived behavioral } \\
\text { control } \rightarrow \text { Moral } \\
\text { obligation }\end{array}$ & 0.036 & .055 & 0.659 & .510 & -0.054 & 0.126 & .036 \\
\hline $\begin{array}{l}\text { Subjective norms } \rightarrow \\
\text { Moral obligation }\end{array}$ & -0.486 & .088 & -5.530 & .000 & -0.631 & -0.342 & -.310 \\
\hline $\begin{array}{l}\text { Positive attitude } \rightarrow \\
\text { Moral obligation }\end{array}$ & -0.363 & .077 & -4.716 & .000 & -0.490 & -0.237 & -.233 \\
\hline $\begin{array}{l}\text { Gender } \rightarrow \text { Moral } \\
\text { disengagement- } \\
\text { overall score }\end{array}$ & 0.055 & .080 & 0.687 & .492 & -0.077 & 0.187 & .027 \\
\hline $\begin{array}{l}\text { Age } \rightarrow \text { Moral } \\
\text { disengagement- } \\
\text { overall score }\end{array}$ & 0.015 & .008 & 1.869 & .061 & 0.002 & 0.029 & .073 \\
\hline $\begin{array}{l}\text { Past piracy behavior } \\
\rightarrow \text { Moral } \\
\text { disengagement- } \\
\text { overall score }\end{array}$ & 0.020 & .024 & 0.865 & .387 & -0.018 & 0.059 & .039 \\
\hline
\end{tabular}


RUNNING HEADER: Abilities and moral disengagement in illegal downloading

Perceived behavioral control $\rightarrow$ Moral

disengagement-

$\begin{array}{lllllll}-0.064 & .032 & -2.017 & .043 & -0.116 & -0.012 & -.100\end{array}$

overall score

Subjective norms $\rightarrow$

Moral

disengagement-

.053

$4.176 \quad .000$

$0.133 \quad 0.307$

.220

overall score

Positive attitude $\rightarrow$

Moral

disengagement-

$\begin{array}{llllll}0.376 & .046 & 8.221 & .000 & 0.301 & 0.451\end{array}$

.379

overall score

Moral obligation $\rightarrow$

Moral

disengagement-

$-0.136$

$.029 \quad-4.696$

$\begin{array}{lll}.000 & -0.184 & -0.089\end{array}$

$-.214$

overall score

Gender $\rightarrow$ Intention

to pirate

$\begin{array}{lllllll}0.077 & .121 & 0.363 & .525 & -0.001 & 0.276 & .022\end{array}$

Age $\rightarrow$ Intention to

pirate

$\begin{array}{lllllll}0.021 & .013 & 1.703 & .089 & 0.085 & 0.042 & .057\end{array}$

Past piracy behavior

$\rightarrow$ Intention to pirate

$\begin{array}{lllllll}0.361 & .036 & 10.112 & .000 & 0.302 & 0.419 & .396\end{array}$

Perceived behavioral control $\rightarrow$ Intention

to pirate

Subjective norms $\rightarrow$ Intention to pirate

Positive attitude $\rightarrow$

Intention to pirate

Moral obligation $\rightarrow$

Intention to pirate

Moral

disengagement-

overall score $\rightarrow$

Intention to pirate

Perceived behavioral

control $\leftrightarrow$ Subjective

norms

Perceived behavioral

control $\leftrightarrow$ Positive

$\begin{array}{lllllll}0.255 & .063 & 4.049 & .000 & 0.151 & 0.358 & .208\end{array}$

attitude

Positive attitude $\leftrightarrow$

$\begin{array}{lllllll}0.222 & .048 & 4.649 & .000 & 0.144 & 0.301 & .200\end{array}$

$\begin{array}{lllllll}0.242 & .081 & 2.974 & .003 & 0.108 & 0.375 & .138\end{array}$

$\begin{array}{lllllll}0.099 & .075 & 1.324 & .185 & -0.024 & 0.222 & .057\end{array}$

$\begin{array}{lllllll}-0.088 & .045 & -1.954 & .051 & -0.162 & -0.014 & -.079\end{array}$

$\begin{array}{lllllll}0.209 & .076 & 2.761 & .006 & 0.085 & 0.334 & .120\end{array}$

$\begin{array}{lllllll}0.536 & .065 & 8.242 & .000 & 0.429 & 0.643 & .455\end{array}$

Subjective norms

\section{Model 5}

Gender $\rightarrow$ Past piracy

behavior

0.868

.186

4.658

.000

0.562

1.175

.226 
RUNNING HEADER: Abilities and moral disengagement in illegal downloading

\begin{tabular}{|c|c|c|c|c|c|c|c|}
\hline $\begin{array}{l}\text { Age } \rightarrow \text { Past piracy } \\
\text { behavior }\end{array}$ & 0.059 & .020 & 2.968 & .003 & 0.026 & 0.091 & .144 \\
\hline $\begin{array}{l}\text { Gender } \rightarrow \text { Attribution } \\
\text { of blame }\end{array}$ & -0.069 & .134 & -0.517 & .605 & -0.290 & 0.151 & -.026 \\
\hline $\begin{array}{l}\text { Age } \rightarrow \text { Attribution of } \\
\text { blame }\end{array}$ & 0.026 & .014 & 1.897 & .057 & 0.004 & 0.049 & .093 \\
\hline $\begin{array}{l}\text { Past piracy behavior } \\
\rightarrow \text { Attribution of } \\
\text { blame }\end{array}$ & 0.160 & .035 & 4.547 & .000 & 0.102 & 0.218 & .229 \\
\hline $\begin{array}{l}\text { Gender } \rightarrow \text { Distortion } \\
\text { of consequences }\end{array}$ & 0.203 & .135 & 1.508 & .131 & -0.019 & 0.424 & .076 \\
\hline $\begin{array}{l}\text { Age } \rightarrow \text { Distortion of } \\
\text { consequences }\end{array}$ & 0.028 & .014 & 1.994 & .045 & 0.005 & 0.051 & .099 \\
\hline $\begin{array}{l}\text { Past piracy behavior } \\
\rightarrow \text { Distortion of } \\
\text { consequences }\end{array}$ & 0.084 & .035 & 2.385 & .016 & 0.026 & 0.142 & .122 \\
\hline $\begin{array}{l}\text { Gender } \rightarrow \text { Moral } \\
\text { justification }\end{array}$ & 0.192 & .111 & 1.733 & .776 & 0.010 & 0.375 & .084 \\
\hline $\begin{array}{l}\text { Age } \rightarrow \text { Moral } \\
\text { justification }\end{array}$ & 0.020 & .012 & 1.766 & .076 & 0.001 & 0.040 & .084 \\
\hline $\begin{array}{l}\text { Past piracy behavior } \\
\rightarrow \text { Moral justification }\end{array}$ & 0.179 & .029 & 6.153 & .000 & 0.131 & 0.227 & .300 \\
\hline $\begin{array}{l}\text { Gender } \rightarrow \\
\text { Euphemistic labelling }\end{array}$ & -0.033 & .115 & -0.284 & .776 & -0.223 & 0.157 & -.013 \\
\hline $\begin{array}{l}\text { Age } \rightarrow \text { Euphemistic } \\
\text { labelling }\end{array}$ & 0.047 & .012 & 3.876 & .000 & 0.027 & 0.066 & .175 \\
\hline $\begin{array}{l}\text { Past piracy behavior } \\
\rightarrow \text { Euphemistic } \\
\text { labelling }\end{array}$ & 0.263 & .030 & 8.688 & .000 & 0.213 & 0.313 & .403 \\
\hline Gender $\rightarrow$ & & & & & & & \\
\hline $\begin{array}{l}\text { Advantageous } \\
\text { comparison }\end{array}$ & -0.027 & .150 & -0.177 & .859 & -0.273 & 0.220 & -.009 \\
\hline $\begin{array}{l}\text { Age } \rightarrow \text { Advantageous } \\
\text { comparison }\end{array}$ & 0.057 & .016 & 3.638 & .000 & 0.031 & 0.083 & .174 \\
\hline $\begin{array}{l}\text { Past piracy behavior } \\
\rightarrow \text { Advantageous } \\
\text { comparison }\end{array}$ & 0.208 & .039 & 5.272 & .000 & 0.143 & 0.273 & .259 \\
\hline $\begin{array}{l}\text { Gender } \rightarrow \text { Diffusion } \\
\text { of responsibility }\end{array}$ & 0.251 & .137 & 1.839 & .065 & 0.027 & 0.476 & .090 \\
\hline $\begin{array}{l}\text { Age } \rightarrow \text { Diffusion of } \\
\text { responsibility }\end{array}$ & 0.056 & .014 & 3.904 & .000 & 0.032 & 0.079 & . 188 \\
\hline $\begin{array}{l}\text { Past piracy behavior } \\
\rightarrow \text { Diffusion of } \\
\text { responsibility }\end{array}$ & 0.138 & .036 & 3.842 & .000 & 0.079 & 0.197 & .190 \\
\hline $\begin{array}{l}\text { Gender } \rightarrow \\
\text { Displacement of }\end{array}$ & 0.182 & .131 & 1.394 & . 162 & -0.033 & 0.397 & .069 \\
\hline
\end{tabular}


RUNNING HEADER: Abilities and moral disengagement in illegal downloading

responsibility

Age $\rightarrow$ Displacement

of responsibility

$\begin{array}{lllllll}0.052 & .014 & 3.786 & .000 & 0.029 & 0.074 & .183\end{array}$

Past piracy behavior

$\rightarrow$ Displacement of

responsibility

Gender $\rightarrow$ Intention

to pirate

Age $\rightarrow$ Intention to

pirate

Past piracy behavior

$\rightarrow$ Intention to pirate

Attribution of blame

$\rightarrow$ Intention to pirate

Distortion of

consequences $\rightarrow$

Intention to pirate

Moral justification $\rightarrow$

Intention to pirate

Euphemistic labelling

$\rightarrow$ Intention to pirate

Advantageous

comparison $\rightarrow$

Intention to pirate

Diffusion of

responsibility $\rightarrow$

Intention to pirate

Displacement of

responsibility $\rightarrow$

Intention to pirate

Attribution of blame

$\leftrightarrow$ Distortion of

0.136

.034

3.969

.000

0.080

0.193

.197

$$
0.27
$$

.123

2.249

.025

$0.074 \quad 0.479$

.079

$\begin{array}{lllllll}0.032 & .013 & 2.469 & .014 & 0.011 & 0.053 & .086\end{array}$

$\begin{array}{lllllll}0.431 & .035 & 12.441 & .000 & 0.374 & 0.489 & .473\end{array}$

$\begin{array}{lllllll}0.059 & .065 & 0.910 & .363 & -0.048 & 0.167 & .045\end{array}$

$\begin{array}{lllllll}0.007 & .058 & 0.127 & .299 & -0.088 & 0.103 & .006\end{array}$

0.187

.084

(n)

$\begin{array}{lllllll}0.387 & .069 & 5.598 & .000 & 0.273 & 0.500 & .277\end{array}$

$\begin{array}{lllllll}-0.049 & .057 & -0.860 & .390 & -0.143 & 0.045 & -.043\end{array}$

consequences

Attribution of blame

$\leftrightarrow$ Moral justification

$\begin{array}{rrrrrrr}0.033 & .069 & 0.470 & .638 & -0.081 & 0.147 & .026 \\ -0.077 & .065 & -1.184 & .236 & -0.183 & 0.030 & -.058\end{array}$

$\begin{array}{lllllll}0.801 & .093 & 8.627 & .000 & 0.648 & 0.954 & .481\end{array}$

$\begin{array}{lllllll}0.950 & .084 & 11.317 & .000 & 0.812 & 1.088 & .691\end{array}$

Attribution of blame

$\leftrightarrow$ Euphemistic

$\begin{array}{lllllll}0.687 & .080 & 8.630 & .000 & 0.556 & 0.818 & .481\end{array}$

labelling

Attribution of blame

$\leftrightarrow$ Advantageous

comparison

Attribution of blame

$\leftrightarrow$ Diffusion of

$\begin{array}{lllllll}0.718 & .092 & 7.779 & .000 & 0.566 & 0.869 & .425\end{array}$

responsibility

Attribution of blame

$\leftrightarrow$ Displacement of

$\begin{array}{lllllll}0.864 & .103 & 8.401 & .000 & 0.695 & 1.034 & .466\end{array}$

$\begin{array}{lllllll}0.531 & .085 & 6.208 & .000 & 0.390 & 0.671 & .328\end{array}$ 
RUNNING HEADER: Abilities and moral disengagement in illegal downloading

responsibility

Distortion of

consequences $\leftrightarrow$

0.605

.076

7.988

.000

0.481

0.730

.438

Moral justification

Distortion of

consequences $\leftrightarrow$

0.592

.078

7.594

.000

$0.464 \quad 0.721$

.413

Euphemistic labelling

Distortion of

consequences $\leftrightarrow$

Advantageous

$0.988 \quad .106$

9.314

.000

$0.814 \quad 1.163$

.530

comparison

Distortion of

consequences $\leftrightarrow$

Diffusion of

0.9

$$
.097
$$

9.419

.000

$0.753 \quad 1.072$

.537

responsibility

Distortion of

consequences $\leftrightarrow$

Displacement of

0.65

responsibility

Moral justification $\leftrightarrow$

Euphemistic labelling

$\begin{array}{lllllll}0.705 & .069 & 10.185 & .000 & 0.591 & 0.819 & .596\end{array}$

Moral justification $\leftrightarrow$

Advantageous

comparison

Moral justification $\leftrightarrow$

Diffusion of

responsibility

Moral justification $\leftrightarrow$

Displacement of

$0.516 \quad .072$

$0.765 \quad .086$

8.860

.000

$0.623 \quad 0.908$

.497

responsibility

Euphemistic labelling

$\leftrightarrow$ Advantageous

comparison

Euphemistic labelling

$\leftrightarrow$ Diffusion of

0.642

.077

8.286

.000

$0.514 \quad 0.967$

.458

responsibility

Euphemistic labelling

$\leftrightarrow$ Displacement of

responsibility

Advantageous

comparison $\leftrightarrow$

Diffusion of

$\begin{array}{lllllll}0.787 & .090 & 8.787 & .000 & 0.640 & 0.934 & .492\end{array}$

$\begin{array}{lllllll}0.691 & .081 & 8.537 & .000 & 0.558 & 0.824 & .475\end{array}$

$\begin{array}{lllllll}0.527 & .075 & 7.039 & .000 & 0.404 & 0.650 & .378\end{array}$

responsibility

Advantageous

comparison $\leftrightarrow$

Displacement of

$\begin{array}{lllllll}1.168 & .112 & 10.452 & .000 & 0.985 & 1.352 & .617 \\ & & & & & & \\ 0.997 & .104 & 9.594 & .000 & 0826 & 1.167 & .550\end{array}$


RUNNING HEADER: Abilities and moral disengagement in illegal downloading

responsibility

Diffusion of

responsibility $\leftrightarrow$

Displacement of

$\begin{array}{llllll}1.120 & .100 & 11.183 & .000 & 0.955 & 1.285\end{array}$

.679

responsibility

Note: Model 1: TPB model with covariates; Model 2: TPB model with covariates integrated with moral obligation; Model 3: TPB model with covariates integrated with moral obligation and moral disengagement subcomponents; Model 4: TPB model with covariates integrated with moral obligation and moral disengagement overall score; model 5: intention to pirate predicted by moral disengagement subcomponents only and covariates; $\rightarrow$ indicates regression, $\leftrightarrow$ indicates correlation.

\section{Model 1}

As indicated, in Model 1, intention to pirate received significant and positive influences from age, past piracy behaviour, perceived behavioural control, subjective norms, and positive attitude toward piracy, but not from gender, which had no significant effect. In relation to the variables of the TPB model, perceived behavioural control received significant and positive influences from gender, age, and past piracy behaviour, whereas subjective norms and positive attitude toward piracy received significant and positive influences from age and past piracy behaviour, but not from gender, which had no significant effect. The three TPB constructs were significantly and positively correlated. Past piracy behaviour was significantly and positively influenced by gender and age. Fit indices indicated a good fit between the theoretical and the empirical model: $\chi^{2}(1)=$ 0.110, $p=$ n.s.; CFI $=1.000 ;$ RMSEA $=0.000[0.000,0.093]$; $\mathrm{SRMR}=0.003$. The model explained a high proportion of the variance of the intention to pirate (explained variance: $56.9 \%$ ).

\section{Model 2}

Model 2 concerned the role of moral obligation. When moral obligation was integrated into the TPB model, it had a significant and negative influence on intention to pirate and received significant and negative influences from age, past piracy behaviour, subjective norms, and positive attitude toward piracy, whereas gender and perceived behavioural control had no 
RUNNING HEADER: Abilities and moral disengagement in illegal downloading

significant effects. For the remaining paths, the pattern of influences was the same as that of Model 1. Fit indices indicated a good fit between the theoretical and the empirical model: $\chi^{2}(1)=$ $0.110, p=$ n.s.; $\mathrm{CFI}=1.000 ; \mathrm{RMSEA}=0.000[0.000,0.093]$; $\mathrm{SRMR}=0.003$. The model explained a high proportion of the variance of the intention to pirate (explained variance: $57.6 \%$ ).

\section{Model 3}

In Model 3, moral disengagement subcomponents were added to the second model. Here, intention to pirate received significant and positive influences from past piracy behaviour, perceived behavioural control, subjective norms, and the moral disengagement mechanism of euphemistic labelling. No other paths were significant. Attribution of blame and moral justification received significant and positive influences from subjective norms and positive attitude toward piracy and a significant and negative influence from moral obligation; all the other paths for these mechanisms were not significant. Distortion of consequences received a significant and positive influence from positive attitude toward piracy and significant and negative influences from perceived behavioural control and moral obligation; no other paths for this mechanism were significant. Euphemistic labelling received significant and positive influences from past piracy behaviour, subjective norms, and positive attitude toward piracy and a significant and negative influence from moral obligation; all the other paths for this mechanism were not significant. Advantageous comparison received significant and positive influences from age, past piracy behaviour, subjective norms, and positive attitude toward piracy and significant and negative influences from perceived behavioural control and moral obligation; the path from gender was not significant. Diffusion of responsibility received significant and positive influences from gender, age, subjective norms, and positive attitude toward piracy and significant and negative influences from perceived behavioural control and moral obligation; the 
RUNNING HEADER: Abilities and moral disengagement in illegal downloading

path from past piracy behaviour was not significant. Displacement of responsibility received significant and positive influences from age, subjective norms, and positive attitude toward piracy and a significant and negative influence from perceived behavioural control; the paths from gender, past piracy behaviour, and moral obligation were not significant. The seven mechanisms of moral disengagement were significantly and positively correlated.

Moreover, as in Model 2, moral obligation had a significant and negative influence on intention to pirate and received significant and negative influences from age, past piracy behaviour, subjective norms, and positive attitude toward piracy, whereas gender and perceived behavioural control had no significant effects. In relation to the variables of the TPB model, as in Models 1 and 2, perceived behavioural control received significant and positive influences from gender, age, and past piracy behaviour, whereas subjective norms and positive attitude toward piracy received significant and positive influences from age and past piracy behaviour, but not from gender, which had no significant effect; moreover, the three TPB constructs were significantly and positively correlated. Past piracy behaviour was significantly and positively influenced by gender and age. Fit indices indicated a good fit between the theoretical and the empirical model: $\chi^{2}(1)=0.110, \mathrm{p}=$ n.s.; $\mathrm{CFI}=1.000 ; \mathrm{RMSEA}=0.000[0.000,0.093]$; $\mathrm{SRMR}=$ 0.002. The model explained a high proportion of the variance of the intention to pirate (explained variance: $60.5 \%)$.

\section{Model 4}

In Model 4, in which the TPB model was integrated with moral obligation and moral disengagement-overall score, intention to pirate received significant and positive influences from past piracy behaviour, perceived behavioural control, subjective norms, and moral disengagement-overall score; moreover, it received a significant and negative influence from 
RUNNING HEADER: Abilities and moral disengagement in illegal downloading

moral obligation. No other paths from gender, age, and positive attitude toward piracy were significant. Moral disengagement-overall score received significant and positive influences from subjective norms and positive attitude toward piracy, whereas it received significant and negative influences from perceived behavioural control and moral obligation. The paths from gender, age, and past piracy behaviour were not significant. Moreover, as in Models 2 and 3, moral obligation had a significant and negative influence on intention to pirate and received significant and negative influences from age, past piracy behaviour, subjective norms, and positive attitude toward piracy, whereas gender and perceived behavioural control had no significant effects. In relation to the variables of the TPB model, as in Models 1,2, and 3, perceived behavioural control received significant and positive influences from gender, age, and past piracy behaviour, whereas subjective norms and positive attitude toward piracy received significant and positive influences from age and past piracy behaviour, but not from gender, which had no significant effect. As before, the three TPB constructs were significantly and positively correlated. Past piracy behaviour was significantly and positively influenced by gender and age. Fit indices indicated a good fit between the theoretical and the empirical model: $\chi^{2}(1)=0.110, p=n . s . ; C F I$ $=1.000 ;$ RMSEA $=0.000[0.000,0.093] ;$ SRMR $=0.003$. The model explained a high proportion of the variance of the intention to pirate (explained variance: $58.4 \%$ ).

\section{Model 5}

Finally, in Model 5, in which intention to pirate was predicted by moral disengagement subcomponents only, the outcome variable received significant and positive influences from gender, age, past piracy behaviour, moral justification, and euphemistic labelling; all the other paths were not significant. Attribution of blame and moral justification received a significant and positive influence from past piracy behaviour, but it did not receive significant influences from 
RUNNING HEADER: Abilities and moral disengagement in illegal downloading

gender or age. Distortion of consequences, euphemistic labelling, advantageous comparison, diffusion of responsibility, and displacement of responsibility received significant and positive influences from age and past piracy behaviour but did not receive a significant influence from gender. The seven mechanisms of moral disengagement were significantly and positively correlated. Past piracy behaviour was significantly and positively influenced by gender and age.

Fit indices indicated a good fit between the theoretical and the empirical model: $\chi^{2}(1)=0.110, p$ $=$ n.s.; $\mathrm{CFI}=1.000 ; \mathrm{RMSEA}=0.000[0.000,0.093] ; \mathrm{SRMR}=0.002$. The model explained a high proportion of the variance of the intention to pirate (explained variance: $56.0 \%$ ).

\section{DISCUSSION AND CONTRIBUTIONS}

This study provides original evidence regarding the role of moral disengagement in the prediction of piracy with respect to the TPB constructs and moral obligation. A first overview is offered by simple correlation results. The following variables exhibit the strongest positive association with intention: subjective norms and perceived behavioural control from the TPB model, past piracy behaviour, and the moral disengagement mechanism of euphemistic labelling. Positive attitude and moral obligation are only moderately associated with intention to pirate, together with other moral disengagement mechanisms and the moral disengagement-overall score. Comparisons between the tested models clearly indicate that moral disengagement mechanisms play a significant role in the prediction of piracy. The magnitude order of the variances explained by the different models are $56 \%$ for the Model 5 (moral disengagement subcomponents + past piracy behaviour + age + gender), $56.9 \%$ for the Model 1 (TPB constructs + past piracy behaviour + age + gender), $57.9 \%$ for the Model 2 (Model $1+$ moral obligation), $58 \%$ for the Model 4 (Model $2+$ moral disengagement overall score), and $60.5 \%$ for the Model 3 (Model $2+$ moral disengagement subcomponents). These results highlight the 
RUNNING HEADER: Abilities and moral disengagement in illegal downloading

predictive contribution of the moral disengagement subcomponents and, similar to previous results, that moral disengagement mechanisms have higher effect sizes than the general moral disengagement score (see Lowry et al., 2017). Moreover, the integration of the SCT with the TPB has more explanatory power in comparison with the other models.

Past piracy behaviour is positively influenced by both age and gender. In line with previous research that characterised pirates as young and male (see Lowry et al., 2017), our study confirms that in the past pirates could be described by age and gender. Nevertheless, an interesting result is the nonsignificant effect of gender on intention across all the tested models, whereas young age has a positive influence on intention in both Model 1 and Model 2, before moral disengagement is accounted for. Furthermore, both subjective norms and positive attitude receive significant and positive influences from age and past piracy behaviour but not from gender, thus indicating that gender no longer influences social norms and dispositions. Taken together, these results clearly indicate that the culture of illegal downloading is spreading across genders and that, next to the young age, pirates are significantly described by experience and abilities in the downloading of digital material (Rutter \& Bryce, 2008). Indeed, when moral disengagement mechanisms are included in the model (Model 3), intention to pirate is explained by past piracy behaviour, perceived behavioural control, subjective norms, and the moral disengagement mechanism of euphemistic labelling, which in turn is positively influenced by previous experience, subjective norms, and positive attitude toward piracy.

The results of our study show that consumer cognition is adapting to the new download culture by resorting to moral-control deactivation mechanisms in a way that strongly reflects a need to disengage from previous moral standards and beliefs. Before moral disengagement mechanisms are entered into the model, moral obligation is indeed a significant negative 
RUNNING HEADER: Abilities and moral disengagement in illegal downloading

predictor of intention. As described by Bandura (1999), euphemistic language is a strategy commonly used by mass media in the presentation of the most delicate news (e.g., in the context of war, mass media use the term 'collateral damage' to describe the killing of innocent civilians), and such neutralising representations often have the effect of lowering public moral concern and awareness. Similarly, when people adopt sanitising labels, they rely on the generative power of language to promote a different perspective on a certain issue. The effects of euphemistic labelling may therefore not be limited to individuals' moral disengagement (ibid.). Euphemistic labelling has the potential to generate new social representations of what is considered immoral, and it thus provides counterarguments to advertising designed to strengthen consumers' sense of moral obligation. The diffusion of such cognitive mechanisms of moral disengagement among current and potential pirates reveals some of the reasons why communication efforts to combat piracy have been proven ineffective. The significant impact of subjective norms on such mechanisms of moral disengagement, together with the role of experience and of perceived piracy abilities, lends support to the thesis of the spread of new download-culture values and of the potential for continued growth of piracy across segments as people acquire the necessary skills to engage in it. Interestingly, perceived behavioural control is significantly and negatively associated with moral disengagement, suggesting that the more people develop abilities and feel in control, the less their intention to pirate requires them to disengage morally. The future of piracy could be further explained by a form of motivation that is based mainly on performance confidence and positive-outcome expectations rather than on ethical and moral reasoning.

The implications for marketing and public policy are twofold. On one hand, these results show an ongoing revolution in the way copyright infringements are labelled and conceived by consumers, despite all the communication efforts made by the film and music industries. It could 
RUNNING HEADER: Abilities and moral disengagement in illegal downloading

be argued that in the absence of such efforts, the phenomenon of piracy could have become even more widespread and frequent; thus, investments in this direction should receive further consideration. Based on our results, communication efforts should specifically address the effect of sanitising language used to detract from the emotional intensity of the reality being referenced. To address moral disengagement, communication should reinforce perceptions of the seriousness of piracy by designing emotionally involving messages that show and describe the consequences of piracy on intellectual property businesses and on the people associated with them. On the other hand, in accordance with recent research (Watson et al. 2016; De Corte \& Van Kenhove, 2017), piracy intentions may be more strongly associated with perceived abilities and envisaged benefits than with moral reasoning. The aging of the millennial generation may correspond to the consolidation of piracy practices. Public policy and marketing should therefore consider solutions tailored to the new Internet-market norms. For instance, they might take into account the different perceptions of the cost structure of digital products, the different perceptions of price fairness, and the increasing demand for free content (Fassnacht et al., 2016; Huang, Chang \& Chen 2005; Lo et al., 2014; Nunes et al.; 2004; Santillanes and Felder, 2015).

\section{Limitations}

Despite its strengths, our study has some limitations, but these also point to compelling future research opportunities. First, as in previous studies, we adopted self-reported measures. More ecologically valid methods would be useful for assessing the truthfulness of the participants' reported information.

Second, although cross-sectional studies can be used to investigate intention to pirate, some of these factors may not be strong predictors of actual behaviour. To address this concern, we recommend longitudinal studies. In doing so, researchers should consider gathering not just 
RUNNING HEADER: Abilities and moral disengagement in illegal downloading

self-report behaviour data but also observed behaviour data.

Third, data from larger samples and with a different recruitment method that guarantee random selection and higher representativeness would allow the generalizability of the present results. With a larger dataset, latent variable analysis could have been adopted instead of path analysis so to reduce the risk of parameter estimates biases. Moreover, longitudinal designs would support further investigation of the relation between perceived behavioural control and moral reasoning. As discussed above, the significance of moral disengagement, and in particular of euphemistic labelling, reflects a cultural change that may result in further diffusion of piracy across the population as people acquire the necessary skills and become more confident. Careful monitoring of the skills associated with piracy and of the individual and motivational factors involved in their acquisition should facilitate the prediction of future trends.

Finally, our study's result can only be expected to generalize to the Italian populations we sampled. Caution thus is urged in expecting similar results in different national cultural samples, as culture and national legal frameworks can have a significant effect on media piracy. We thus urge researchers to consider testing our models in highly relevant national cultural contexts such as China, the United States, Northern Europe, South America, Africa, and the Middle East.

\section{ETHICAL APPROVAL:}

All procedures performed in this study were in accordance with the ethical standards of our institutional committees and with the 1964 Helsinki declaration and its later amendments or comparable ethical standards. 
RUNNING HEADER: Abilities and moral disengagement in illegal downloading

\section{REFERENCES}

Ajzen, I. (1985). From intentions to Actions: A theory of planned behavior. In P. D. J. Kuhl \& D.

J. Beckmann (Eds.), Action Control, 11-39. Berlin, Heidelberg: Springer.

Ajzen, I. (1991). The theory of planned behavior. Organizational Behavior and Human Decision Processes, 50(1), 179-211.

Ajzen, I. (2002a). Perceived behavioral control, self-efficacy, locus of control, and the theory of planned behavior. Journal of Applied Social Psychology, 32(4), 665-683.

Ajzen, I. (2002b). Residual effects of past on later behavior: Habituation and reasoned action perspectives. Personality and Social Psychology Review, 6(2), 107-122.

Al-Rafee, S., \& Cronan, T. P. (2008). Factors that influence the intention to pirate software and media. Journal of Business Ethics, 78(4), 527-545.

Aquino, K., \& Reed, A. II. (2002). The self-importance of moral identity. Journal of Personality and Social Psychology, 83(6), 1423-1440.

Bamberg, S., Ajzen, I., \& Schmidt, P. (2003). Choice of travel mode in the theory of planned behavior: The roles of past behavior, habit, and reasoned action. Basic and Applied Social Psychology, 25(3), 175-187. 
RUNNING HEADER: Abilities and moral disengagement in illegal downloading

Bandura, A. (1991). Social cognitive theory of self-regulation. Organizational Behavior and Human Decisions Sciences 50(2), 248-287.

Bandura, A. (1997). Self-efficacy: The Exercise of Control. New York, NY: Freeman.

Bandura, A. (1999). Moral disengagement in the perpetration of inhumanities. Personality and Social Psychology Review, 3(3), 193-209.

Bandura, A. (2001). Social-cognitive theory: An agentic perspective. Annual Review of Psychology, 52(1), 1-26.

Bandura, A. (2002). Selective moral disengagement in the exercise of moral agency. Journal of Moral Education, 31(2), 101-119.

Bandura, A., Barbaranelli, C., Caprara, G. V., \& Pastorelli, C. (1996). Mechanisms of moral disengagement in the exercise of moral agency. Journal of Personality and Social Psychology, $71(2), 364-374$.

Bandura, A., Caprara G.V., Barbaranelli, C., Pastorelli, C., Iafrate, C., Beretta, M., \& Steca, P. (2006). La misura del disimpegno morale nel contesto delle trasgressioni dell'agire quotidiano, Giornale Italiano Di Psicologia, XXXIII (1), 83-106. 
RUNNING HEADER: Abilities and moral disengagement in illegal downloading

Banerjee, D., Cronan, T. P., \& Jones, T. W. (1998). Modeling IT ethics: A study in situational ethics. MIS Quarterly, 22(1), 31-60.

Beck, L., \& Ajzen, I. (1991). Predicting dishonest actions using the theory of planned behavior. Journal of Research in Personality, 25(3), 285-301.

Bhattacharjee, S., Gopal, R.D., \& Sanders G.L. (2003). Digital music and online sharing: Software piracy 2.0? Communications of the ACM, 46(7), 107-111.

Bodur, H. O., Brinberg, D., \& Coupey, E. (2000). Belief, affect, and attitude: Alternative models of the determinants of attitude. Journal of Consumer Psychology, 9(1), 17-28.

Bonner, S., \& O'Higgins, E. (2010). Music piracy: Ethical perspectives. Management Decision, 48(9), 1341-1354.

Borja, K., Dieringer, S., Daw, J., (2015). The effect of music streaming services on music piracy among college students, Computers in Human Behavior, 45(April), 69-76.

Chau, P. Y., \& Hu, P. J. H. (2001). Information technology acceptance by individual professionals: A model comparison approach. Decision sciences, 32(4), 699-719.

Chiang, E.P., Assane, D. (2008). Music piracy among students on the university campus: Do males and females react differently? Journal of Socio-Economics, 37(4), 1371-1380. 
RUNNING HEADER: Abilities and moral disengagement in illegal downloading

Chiou, J. S., Huang, C. Y., \& Lee, H. H. (2005). The antecedents of music piracy: Attitudes and intentions. Journal of Business Ethics, 57(2), 161-174.

Cohen, J. (1988). Statistical Power Analysis for the Behavioral Sciences (2nd ed.). Lawrence Erlbaum Associates, Hillsdale, NJ.

Condry, I. (2004). Cultures of music piracy an ethnographic comparison of the US and Japan. International Journal of Cultural Studies, 7(3), 343-363.

Conner, M. and Armitage, C. (1998). Extending the theory of planned behavior: A review and avenues for further research. Journal of Applied Social Psychology, 28(15), 1429-1464.

Coyle, J. R., Gould, S. J., Gupta, P., \& Gupta, R. (2009). "To buy or to pirate": The matrix of music consumers' acquisition-mode decision-making. Journal of Business Research, 62(10), $1031-1037$.

Cronan, T. P., \& Al-Rafee, S. (2008). Factors that influence the intention to pirate software and media. Journal of Business Ethics, 78(4), 527-545.

De Corte, C.E. \& Van Kenhove, P., (2017). One sail fits all? A psychographic segmentation of digital pirates. Journal of Business Ethics, 143(3), 441-465. 
RUNNING HEADER: Abilities and moral disengagement in illegal downloading

Fassnacht, M., Unterhuber, S., (2016). Consumer response to online/offline price differentiation. Journal of Retailing and Consumer Services, 28(1), 137-148.

Fishbein, M., \& Ajzen, I. (1975). Belief, Attitude, Intention, and Behavior: An Introduction to Theory And Research. Reading, MA: Addison Wesley.

Flannery, B. L., \& May, D. R. (2000). Environmental ethical decision making in the US metalfinishing industry. Academy of Management Journal, 43(4), 642-662.

Fleming, P., Watson, S.J., Patouris, E., Bartholomew, K.J., \& Zizzo, D.J. (2017). Why do people file share unlawfully? A systematic review, meta-analysis and panel study. Computers in Human Behavior, 72(July), 535-548.

Giesler, M. (2008). Conflict and compromise: Drama in marketplace evolution. Journal of Consumer Research, 34(6), 739-753.

Go-Gulf (2011, December 29). Online piracy in numbers-Facts and statistics. [Blog post]. Retrieved from https://www.go-gulf.com/blog/online-piracy/, retrieved: March 1, 2018.

Hagger, M. S., Chatzisarantis, N. L., \& Biddle, S. J. (2002). A meta-analytic review of the theories of reasoned action and planned behaviour in physical activity: Predictive validity and the contribution of additional variables. Journal of Sport \& Exercise Psychology, 24(1), 3-32. 
RUNNING HEADER: Abilities and moral disengagement in illegal downloading

Hamrick, K., (2016). The moral implications of software piracy. Student scholarship - Computer science, 2 (December), 1-7. Retrieved from https://digitalcommons.olivet.edu/csis stsc/2, retrieved: March 1, 2018

Hinduja, S. (2003). Trends and patterns among online software pirates. Ethics and Information Technology, 5(1), 49-61.

Hu, L., \& Bentler, P. M. (1998). Fit indices in covariance structure modeling: Sensitivity to under-parameterized model misspecification. Psychological Methods, 3(4), 424-453.

Hu, L., \& Bentler, P. M. (1999). Cutoff criteria for fit indexes in covariance structure analysis: Conventional criteria versus new alternatives. Structural Equation Modeling, 6(4), 1-55.

Huang, J. H., Chang, C. T., \& Chen, C. Y. H. (2005). Perceived fairness of pricing on the Internet. Journal of Economic Psychology, 26(3), 343-361.

Khang, H., Ki, EJ., Park, IK. et al. (2012). Exploring antecedents of attitude and intention toward Internet piracy among college students in South Korea. Asian Journal of Business Ethics, 1(2), $177-194$.

Kurland, N. B. (1995). Ethical intentions and the theories of reasoned action and planned behavior. Journal of Applied Social Psychology, 25(4), 297-313. 
RUNNING HEADER: Abilities and moral disengagement in illegal downloading

Kwak, K., \& Bandura, A. (1997). Role of perceived self-efficacy and moral disengagement in antisocial conduct. Unpublished manuscript, Osan College, Seoul, Korea.

Kwong, T. C., \& Lee, M. K. (2002). Behavioral intention model for the exchange mode internet music piracy. Proceedings of the 35th Annual Hawaii International Conference on System Sciences (HICSS 2002), Big Island, HI, 7-10 January, IEEE, 2481-2490.

LaRose, R., \& Kim, J. (2006). Share, steal, or buy? A social cognitive perspective of music downloading. CyberPsychology \& Behavior, 10(2), 267-277.

Leonard, L. N., \& Cronan, T. P. (2001). Illegal, inappropriate, and unethical behavior in an information technology context: A study to explain influences. Journal of the Association for Information Systems, 1(12), 1-31.

Lo, S.K., Hsieh, A.Y., Chiu, Y.P., (2014). Why expect lower prices online? Empirical examination in online and store-based retailers, International Journal of Electronic Commerce Studies, 5(1), 27-38.

Lowry, P.B., Zhang, J., Wu, T., (2017). Nature or nurture? A meta-analysis of the factors that maximize the prediction of digital piracy by using social cognitive theory as a framework. Computers in Human Behavior, 68(March), 104-120. 
RUNNING HEADER: Abilities and moral disengagement in illegal downloading

MacKinnon, D. P., Lockwood, C. M., \& Williams, J. (2004). Confidence limits for the indirect effect: Distribution of the product and resampling methods. Multivariate Behavioral Research, 39(1), 99-128.

Madden, T. J., Ellen, P. S., \& Ajzen, I. (1992). A comparison of the theory of planned behavior and the theory of reasoned action. Personality and Social Psychology Bulletin, 18(1), 3-9.

Muthén, L. K., \& Muthén, B. O. (1998-2012). Mplus User's Guide. Sixth Edition. Los Angeles, CA: Muthén \& Muthén.

Nunnally, J. C., \& Bernstein, I. H. (1994). Psychometric Theory (3rd ed.). New York, NY: McGraw-Hill.

Nunes, J. C., Hsee, C. K., \& Weber, E. U. (2004). Why are people so prone to steal software? The effect of cost structure on consumer purchase and payment intentions. Journal of Public Policy \& Marketing, 23(1), 43-53.

Ouellette, J. A., \& Wood, W. (1998). Habit and intention in everyday life: The multiple processes by which past behavior predicts future behavior. Psychological Bulletin, 124(1), 5474.

Randall, D. M., \& Gibson, A. M. (1991). Ethical decision making in the medical profession: An application of the theory of planned behavior. Journal of Business Ethics, 10(2), 111-122. 
RUNNING HEADER: Abilities and moral disengagement in illegal downloading

Robertson, K., McNeill, L., Green, J., \& Roberts, C. (2012). Illegal downloading, ethical concern, and illegal behavior. Journal of Business Ethics, 108(2), 215-227.

Rutter, J., \& Bryce, J. (2008). The consumption of counterfeit goods: 'Here be pirates?'. Sociology, 42(6), 1146-1164.

Sang, Y., Lee, J., Kim, Y., \& Woo, H., (2015). Understanding the intentions behind illegal downloading: A comparative study of American and Korean college students, Telematics and Informatics, 32(2), 333-343.

Santillanes, G., \& Felder, R. M. (2015). Software piracy in research: A moral analysis. Science and Engineering Ethics, 21(4), 967-977.

Shiau, W. L., \& Chau, P. Y. (2016). Understanding behavioral intention to use a cloud computing classroom: A multiple model comparison approach. Information \& Management, 53(3), 355-365.

Spark L. (2010). The Demographic Factors Affecting University Students' Intention to Pirate Software. In: J. Berleur, M.D. Hercheui, \& L.M. Hilty (Eds) What Kind of Information Society? Governance, Virtuality, Surveillance, Sustainability, Resilience. IFIP Advances in Information and Communication Technology, 22-32. Berlin, Heidelberg: Springer. 
RUNNING HEADER: Abilities and moral disengagement in illegal downloading

Trafimow, D. (1996). The importance of attitudes in the prediction of college students' intentions to drink. Journal of Applied Social Psychology, 26(24), 2167-2188.

Wang, Y., Yeh, C., Liao, Y., (2013). What drives purchase intention in the context of online content services? The moderating role of ethical self-efficacy for online piracy. International Journal of Information Management, 33(1), 199-208.

Watson, S.J., Zizzo, D.J., Fleming, P. (2015). Determinants of unlawful file sharing: A scoping review. PLoS One, 10(6): e0127921.

Watson, S. J., Zizzo, D. J. \& Fleming, P. (2016). Risk, benefit, and moderators of the affect heuristic in a widespread unlawful activity: Evidence from a survey of unlawful file-sharing behavior. Risk Analysis, 37(6): 1146-1156.

West, S.G., Finch, J.F., \& Curran, P.J. (1995). Structural equation models with nonnormal variables: Problems and remedies. In R. H. Hoyle (Ed.), Structural Equation Modeling: Concepts, Issues, and Applications, 56-75. Thousand Oaks, CA: Sage.

Wingrove, T., Korpas, A. L., \& Weisz, V. (2011). Why were millions of people not obeying the law? Motivational influences on non-compliance with the law in the case of music piracy. Psychology, Crime \& Law, 17(3), 261-276. 
RUNNING HEADER: Abilities and moral disengagement in illegal downloading

Yoon, C. (2011). Theory of planned behavior and ethics theory in digital piracy: An integrated model. Journal of Business Ethics, 100(3), pp. 405-417.

Yoon, C., (2012). Digital piracy intention: A comparison of theoretical models, Behaviour \& Information Technology, 31(6), 565-576. 